IZA DP No. 9648

The Compromise Effect in Action:

Lessons from a Restaurant's Menu

Pia Pinger

Isabel Ruhmer-Krell

Heiner Schumacher

January 2016 


\title{
The Compromise Effect in Action: Lessons from a Restaurant's Menu
}

\author{
Pia Pinger \\ University of Bonn \\ and IZA \\ Isabel Ruhmer-Krell \\ PricewaterhouseCoopers AG \\ Heiner Schumacher \\ KU Leuven \\ Discussion Paper No. 9648
January 2016 \\ IZA \\ P.O. Box 7240 \\ 53072 Bonn \\ Germany \\ Phone: +49-228-3894-0 \\ Fax: +49-228-3894-180 \\ E-mail: iza@iza.org
}

Any opinions expressed here are those of the author(s) and not those of IZA. Research published in this series may include views on policy, but the institute itself takes no institutional policy positions. The IZA research network is committed to the IZA Guiding Principles of Research Integrity.

The Institute for the Study of Labor (IZA) in Bonn is a local and virtual international research center and a place of communication between science, politics and business. IZA is an independent nonprofit organization supported by Deutsche Post Foundation. The center is associated with the University of Bonn and offers a stimulating research environment through its international network, workshops and conferences, data service, project support, research visits and doctoral program. IZA engages in (i) original and internationally competitive research in all fields of labor economics, (ii) development of policy concepts, and (iii) dissemination of research results and concepts to the interested public.

IZA Discussion Papers often represent preliminary work and are circulated to encourage discussion. Citation of such a paper should account for its provisional character. A revised version may be available directly from the author. 


\section{ABSTRACT}

\section{The Compromise Effect in Action: Lessons from a Restaurant's Menu*}

The compromise effect refers to individuals' tendency to choose intermediate options. Its existence has been demonstrated in a large number of hypothetical choice experiments. This paper uses field data from a specialties restaurant to investigate the existence and strength of the compromise effect in a natural environment. Despite the presence of many factors that potentially weaken the compromise effect (e.g., a very large choice set, the opportunity to choose familiar options), we find evidence for it both in descriptive statistics and regression analyses. Options which become a compromise after a change in the choice set gain on average five percent in market share. We also find that the compromise effect is especially pronounced in groups, while for single customers it is statistically insignificant.

JEL Classification: D03, M31

Keywords: utility theory, restaurant data, compromise effect

Corresponding author:

Pia Pinger

Department of Economics

University of Bonn

Adenauerallee 24-42

53113 Bonn

Germany

E-mail: pinger@uni-bonn.de

\footnotetext{
* The authors thank Dirk Engelmann, Johannes Koenen, Julian Krell, Christian Michel, Martin Peitz, Martin Watzinger and the seminar participants at the University of Mannheim for help and useful discussions. Anastasia Moor provided excellent research assistance. Isabel Ruhmer-Krell gratefully acknowledges financial support from the German Science Foundation (DFG). A first version of this paper was written while she was working at the University of Mannheim. Supplementary materials can be found in the Online Appendix.
} 


\section{Introduction}

A crucial assumption of rational choice theory is that decision makers have well-defined preferences over all available options. It implies that a change in the composition of the choice set should not affect the decision maker's preferences over two alternatives. However, a large body of work in psychology and economics shows that this assumption is frequently violated. In many situations, the context matters for choice behavior, i.e., the choice between two alternatives depends on which other options are available. One of the most well-known context effects is the "compromise effect." The compromise effect refers to a tendency to choose non-extreme options. To illustrate, consider Figure 1. Suppose that the original choice set is given by the options $\{v, w, x, y\}$, which differ in two dimensions (such as quality and price). If option $z$ becomes available, option $y$ becomes a compromise: it is no longer the best option with respect to attribute 1 , but also no longer the worst option with respect to attribute 2. A compromise effect occurs if option $y$ is chosen more often after the introduction of $z$ than before.

Figure 1: The Compromise Effect

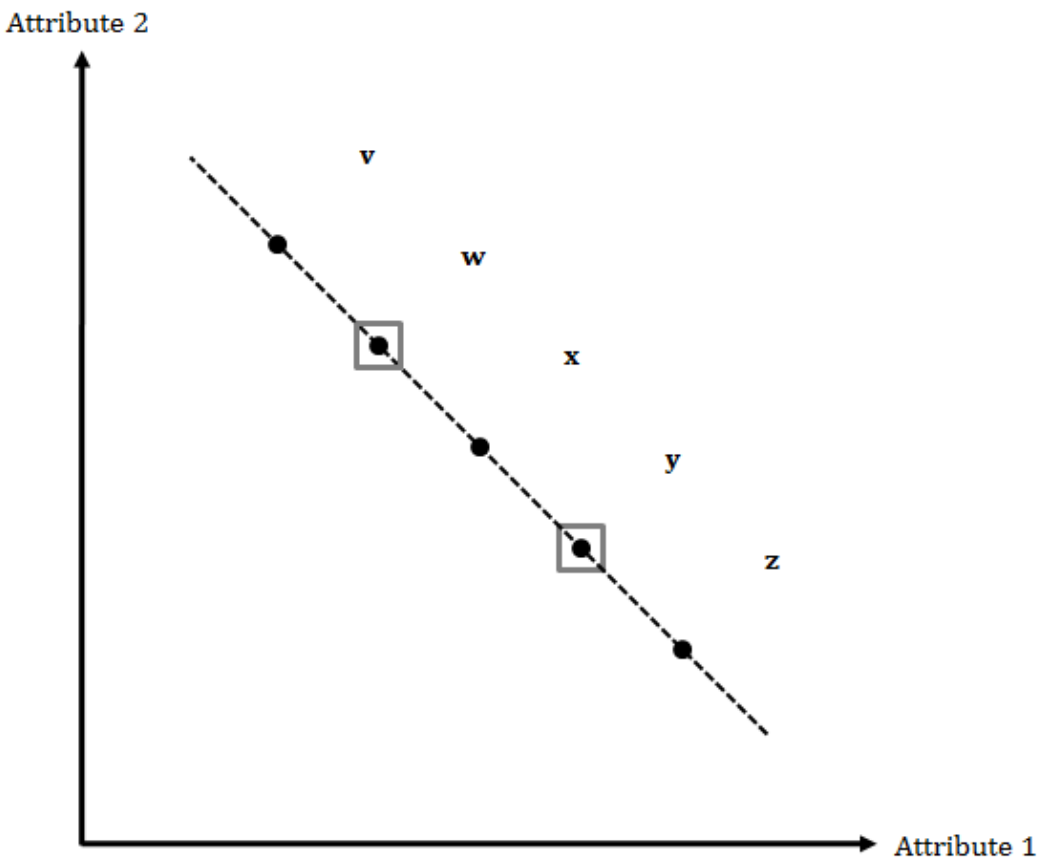

Notes: The squared options $w$ and $y$ turn into compromise options when options $v$ and $z$ are added to the choice set.

The compromise effect was first demonstrated by Simonson (1989). Subsequently, a large experimental literature emerged that studies the scope and magnitude of the compromise effect. It is now considered to be one of the most robust phenomena in behavioral research. Simonson and Nowalis (2000) show that the compromise effect is weaker when subjects are requested to state reasons for their intended choice. They discuss where in such a situation subjects want to present 
reasons (and thus choices) that are less conventional. Dhar et al. (2000) demonstrate that time pressure reduces the extent of the compromise effect. Dhar and Simonson (2003) find that introducing a "no-choice" option weakens or even eliminates the compromise effect. They conjecture that a compromise is chosen especially by those subjects who are uncertain about their preferences. These subjects are more likely to choose the no-choice option than subjects who select extreme options. Similarly, Sheng et al. (2005) find that subjects who are more familiar with a product category are less likely to choose the compromise. Kivetz et al. (2004a) demonstrate that the compromise effect also prevails in larger choice sets with complex alternatives characterized by more than two attributes. Chuang et al. (2012) investigate how recommendations of others affect the extent of the compromise effect. They find that it is weaker when extreme options are recommended to the decision maker. All of these papers use data from hypothetical choice experiments.

In this paper, we examine the compromise effect for the first time in a natural environment. Specifically, we use the cashier data from a German specialties restaurant from a seven-year period. They contain more than 88,000 individual choices. In the restaurant's menu, main dishes are grouped into six categories (such as fish, steaks, etc.). For each category, the options are listed in an ascending-price order. During the observational period, the restaurant changed its menu several times, thereby creating in each category choice set variations that can be used to study the compromise effect.

The considered setting is clearly not conducive for the compromise effect. The customers of the specialties restaurant may invest more cognitive effort into decisions than subjects in hypothetical choice experiments. This may reduce the scope for decision biases (Levitt and List 2007). Moreover, the choice situation - selecting a dish from a restaurant's menu - should be a familiar one to most customers. In addition, all the mentioned sources of influence that potentially weaken the compromise effect are present in our setting: there are many more options on the menu than in the experiments cited above, and there are at least four choices in each food category; customers can pick from categories they know well (e.g., they can choose a well-known dish); no-choice is an option; and when customers arrive in groups, they may discuss their choices or make recommendations to each other.

Despite these adverse factors, we find a significant compromise effect in our data, both in descriptive and regression analyses. On average, it amounts to an increase in market shares of around five percentage points. However, its strength greatly varies between the different food categories, ranging from zero to over one hundred percent. Moreover, we find suggestive evidence that the compromise effect is stronger for customers who dine in groups. For customers who dine alone, we find no statistically significant compromise effect.

Our results are relevant in at least two respects. First, they are of interest to theoretical researchers, who aim at building empirically accurate models for economic choice behavior. Second, they are important to practitioners and marketers, who may exploit the compromise effect to construct choice sets strategically, so that the attractiveness and purchase likelihood of designated high-margin options is maximized. 
The paper contributes to several strands of the literature. A number of papers use behavioral concepts to construct models that capture the compromise effect. ${ }^{1}$ Alternatively, one can explain the compromise effect in a standard model by assuming that the choice set informs consumers about important features of the environment (Wernerfelt 1995, Prelec et al. 1997, Kamenica 2008). The propensity to choose middle options may be due to the fact that some consumers are uncertain about their true preferences, but know that within the customer population they have intermediate tastes. Our data do not allow us to examine the different theories. However, the results provide some support for the idea that the compromise effect is pronounced in product categories consumers do not know well.

We also contribute to a growing literature that documents biased consumption choices using field data and field experiments. ${ }^{2}$ Doyle et al. (1999) use sales data from a grocery store to show that the attraction effect also occurs in a natural environment (the attraction effect refers to an increase in the market share of an option when an alternative becomes available which is strictly dominated by that option, but not by the other options in the original choice set). Iyengar and Lepper (2000) expose shoppers in a grocery store to either limited choice sets (with 6 options) or extensive choice sets (with 24 options). They demonstrate that the availability of too many options discourages choice ("choice overload hypothesis"): Customers in the limited choice set condition were much more likely to actually buy a product than customers in the extensive choice set condition. DellaVigna and Malmendier (2006) analyze the customers' contract choice and attendance at three health clubs. For a large share of customers a per-visit option would be optimal, given their realized attendance. Nevertheless, many of them purchase costly long-term contracts, which implies a monetary loss. The authors show that these customers on average overestimate future attendance when signing the contract. Abeler and Marklein (2015) randomly distribute cash grants and in-kind grants (vouchers

\footnotetext{
${ }^{1}$ Simonson and Tversky (1992) argue that it may be due to "extremeness aversion": Unlike extreme options, compromise options - such as options $w$ and $y$ in Figure 1 when the choice set is $\{v, w, x, y, z\}-$ have no large disadvantages. When disadvantages are weighted more than advantages (as under loss aversion), this feature makes compromises attractive. Tversky and Simonson (1993) derive the compromise effect from a simple utility framework that exhibits two non-standard features, "background" and "choice set" effects. Background (e.g., previous exposure to other choice sets) influences the weight of each dimension in the utility function; the choice set influences the valuation of an option through pairwise comparisons of this option with the alternatives in the choice set. Kivetz et al. (2004a) build four context-dependent choice models, which they estimate and test using experimental data. In particular, they show that these models can better explain the data than traditional choice models that are derived from value maximization. Kivetz et al. (2004b) discuss to what extent their models can be extended to more complex environments, such as group decisions or the purchase of complex products. De Clippel and Eliaz (2012) construct a multiple selves model in which both the compromise and the attraction effect occur as a solution of a bargaining game between different selves, which represent the different quality dimensions. There is also a growing literature on non-standard choice theory that captures empirically relevant phenomena related to the compromise effect. Masatlioglu and Ok (2005) extend rational choice theory by a status quo bias. Rubinstein and Salant (2006) analyze rational choice from lists (rather than sets) where the order of presentation potentially matters for decisions. Manzini and Mariotti (2007) and Apesteguia and Bellester (2013) examine multi-stage decision processes that can rationalize choices that violate the axiom of independence of irrelevant alternatives. In Ehlers and Sprumont (2008) and Lombardi (2008) choices are modeled as the outcome of a tournament, and thus may be cyclic (a fact known as the Condorcet paradox). Salant and Rubinstein (2008) study choice functions that depend on the framing of the problem.

${ }^{2}$ There are many more studies on biases in financial decision making and labor economics; see DellaVigna (2009) and List and Rasul (2010) for reviews.
} 
for beverages) to customers in a restaurant. They find that consumers do not treat these grants as fungible. Instead, they change consumption according to the label of the in-kind grant.

The remainder of this paper is organized as follows. Section 2 formally derives the different measures for the strength of the compromise effect which are commonly used in the literature. Section 3 describes the data set and our empirical strategy. Our results are discussed in Section 4. Section 5 concludes.

\section{Theoretical Framework}

This section defines the notion of the compromise effect within the standard choice framework and derives implications that can be tested with aggregate data. ${ }^{3}$ Let $T$ be the set of all potential options. Each option $x \in T$ has $n$ attributes such as price, taste or quality. Let $x_{i}$ be the score of option $x$ in dimension $i$. A choice function $C(S)$ assigns to every set $S \subset T$ an option that the decision maker chooses (for convenience, we rule out that the decision maker is indifferent between two or more options). A choice function $C$ satisfies "value maximization" if there exists a function $v: T \rightarrow \mathbb{R}$ that assigns a real value to each option so that $x=C(S)$ if and only if $v(x) \geq v(y)$ for all $y \in S$.

An immediate consequence of value maximization is the "independence of irrelevant alternatives" (IIA). An option that is not chosen cannot become the chosen option when new options are added to the choice set. Formally, this means that $x=C(T)$ and $x \in S \subset T$ imply $x=C(S)$. Unfortunately, it is impossible to detect a violation of IIA in aggregate data. The ordering of market shares of two options $x$ and $y$ may reverse under value maximization when a new option becomes available. ${ }^{4}$ We therefore examine the implications of value maximization for the market share of an option under varying choice sets.

A second consequence of value maximization is "regularity": The market share of an option $x$ cannot increase when new options are added to the choice set. Define by $P(x ; T)$ the market share of option $x$ if the choice set is given by $T$, and by $P(S ; T)$ the sum market shares of the options in $S \subset T$ if the choice set is $T$. Regularity then means that $x \in S \subset T$ implies $P(x ; S) \geq P(x ; T)$. This inequality is most commonly used to detect violations of value maximization. In particular, the difference $\Delta P_{1}(x)=P(x ; T)-P(x ; S)$ is used as a measure for the compromise effect.

There exists yet another implication of value maximization for aggregate data, but it requires stronger assumptions on the value function $v$. Suppose that $v$ is defined over an option's attributes, $v(x)=v\left(x_{1}, \ldots, x_{n}\right)$, and that it continuously increases in each attribute. We say that option $y$ "lies in between option $x$ and $z$ " if its attribute scores are such that $x_{i} \leq y_{i} \leq z_{i}$ for each dimension $i$.

\footnotetext{
${ }^{3}$ In this section, we follow and extend the framework of Tversky and Simonson (1993).

${ }^{4}$ To illustrate, assume that $x$ is chosen more often than $y$ when only these two options are available. Now add option $z$ to the choice set. The ordering of market shares of $x$ and $y$ reverses if those consumers who originally chose $x$ strictly prefer $z$ to $x$, while those consumers who originally chose $y$ strictly prefer $y$ to $z$.
} 
Define the "popularity" of $y$ relative to $x$ in the choice set $S$ by

$$
P(y, x ; S)=\frac{P(y ; S)}{P(y ; S)+P(x ; S)} .
$$

Under an additional weak assumption - the "ranking condition" - option y loses relatively more in terms of market share than option $x$ when $z$ is introduced. ${ }^{5}$ To capture this formally, define by $S$ and $T$ two choice sets where $T=S \cup\{z\}$. If the ranking condition and value maximization is satisfied, then $y$ lying in between $x$ and $z$ implies $P(y, x ; S) \geq P(y, x ; T)$. The difference $\Delta P_{2}(y)=$ $P(y, x ; T)-P(y, x ; S)$ therefore is our second measure for the compromise effect. If there are more than two options in set $S$, measure $\Delta P_{2}$ can be defined for all options $x$ with $x_{i} \leq y_{i}$ in each dimension $i$. We construct a third measure for the compromise effect that uses this fact. Denote by $S-y$ the set that contains all options from $S$ except $y$ and assume that for each option $x \in S-y$ it holds that $y$ lies between $x$ and $z$. Then value maximization and the ranking condition imply that $P(y, S-y ; S) \geq P(y, S-y ; T)$. The difference $\Delta P_{3}(y)=P(y, S-y ; T)-P(y, S-y ; S)$ is then our third measure for the compromise effect.

\section{Data and Empirical Strategy}

\subsection{Data}

Our data originate from a German specialties restaurant located in a rural area of North-Eastern Germany. ${ }^{6}$ According to the owner, at most 25 percent of customers visit the restaurant on a regular basis (around once a month); all other customers are tourists who use the restaurant as a day-trip destination. $^{7}$

The restaurant provided two datasets. The first dataset includes all the restaurant's bills from January 5, 2002 until May 29, 2009. They contain 88,113 individual choices of main dishes. We can, in addition, extract the amount and prices of dishes ordered, the total billing amount, date and time, table number and the name of the waiter.

The second dataset is the menus that were offered to customers during the observational period. In total, there were 21 different menus. Each menu contains between 24 and 30 main dishes. These were grouped into six separate categories: traditional, fish, venison, steaks, poultry and vegetarian. Within each category, the available dishes are listed according to price, starting with the cheapest option. Figure 2 shows several examples. From these menus we can extract information about the exact position of each item within each category. ${ }^{8}$

\footnotetext{
${ }^{5}$ See the Online Appendix for details.

${ }^{6}$ The exact name and location is not disclosed in agreement with the restaurant's owner. Aggregation of the available data could otherwise allow local competitors to take advantage of financial figures.

${ }^{7}$ This is supported by Table 1, which shows that $57 \%$ of all menu choices were made on weekends.

${ }^{8}$ The categories remained the same over time even though the category names varied slightly (see Figure 2). One dish (chicken breast fillet) was listed in two categories (poultry and steaks) in three menus. In those cases we randomly assigned half of the observations to each of the categories.
} 


\section{Example page from menu 7:}

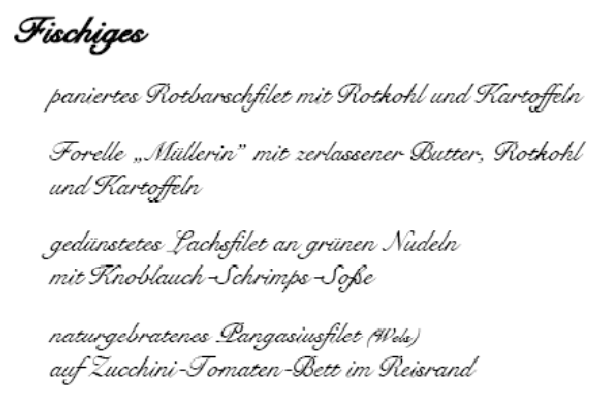

\section{Wildgerichte}

WVildgulasch mit Rothohl und Triodeln

Avildschweinbraten mit Rothoth und RTopen

Rirschbuten mit Waldpreiselbeeren', Trohetten und Waldpilzen

Sperialitit des Frauses.

Tagotherremplatte

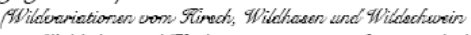

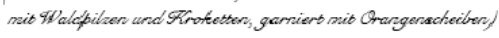

\section{Example page from menu 14:}

\section{Fischiges aus Fluss und Meer}

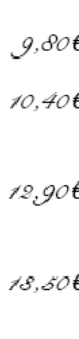

gebackene Sinterfischringe auf Salat

$7.50 €$

mit Knoblauchdip und Goast

paniertes Rotbarsclyfilet

mit Apfelrothohl und Trartoffeln

9.906

Forelle "Nallerin" mit zerlassener Quutter,

Tpfelrothohl und Tartoffeln

Tasta mit Riesengarnelen

in einer tomatigen Finoblauch-Sahne-Sofe

gebratenas Rangasieusfles (Wicle)

mit Rieis, Broccoti und Dill-Sahne-Sofe

Wildspexialitäten

$10.70 €$

$11.90 €$

Wildschweinbraten

mit Apflirathothi und Trlopen

$12,80 €$

Rirschbraten mit Midpreiselbeeren',

Frotetten und Mialdpilzen

$18.90 €$

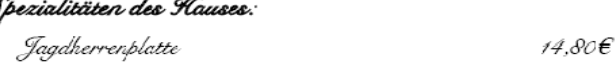

Mildrariationen wom Rirsch, Wildhasen

und Widschwein mit W aldpilzen und Frotettens, garniero mit Orangenocheiben)

Bionbuaten

mit Tildpilsen, Affelrothoth und Trotetten
$10,60 €$

$12.50 €$

$12.90 €$

$12,50 €$

$12.90 €$

$14,80 €$

$7.50 €$

Figure 2: Examples of menu pages

Tables 1 and 2 summarize the main variables of interest as well as the most important controls. The average price of a chosen main dish is EUR 10.05, with a standard deviation of about EUR 2.60. About 38 percent of the chosen items are located at the middle position within their menu category while only less than 25 percent are either in first or last position. ${ }^{9}$ Splitting this up by category, column 10 of Table 2 shows that between 25 and 54 percent of the customers chose the middle position of a category. When compared to the random share of middle positions available in each category (column 3 of Table 2) the median is chosen relatively more often.

\section{[Insert Tables 1 and 2 about here]}

Our observations are table-wise restaurant bills. In most cases, they reflect individual choices made in the presence of a group. The data do not contain information about these groups except for their approximate size as measured by the total number of main dishes listed on the bill. On

\footnotetext{
${ }^{9}$ The large fraction of items in the middle position (median position within category) partly results from its definition. The middle position is defined such that it equals the median whenever there is an unequal number of items. When there is an equal number of items within a category, the two middle items are both defined to be at the median position within the category.
} 
average, individuals come in groups of three or four (the average number of main dishes per bill is 3.62 ). Only 7.13 percent of all bills contained a single main dish.

As control variables we use regional weather data on the average daily temperature, macroeconomic indicators on the monthly unemployment rate at the district level, and an index measuring the business climate on the national level.

\subsection{Quasi-Experimental Cases}

We use the variations in the menus to test the existence and the size of the compromise effect. In general, there can be many modifications in each category. We therefore start by focusing on "pure" cases in which a category is expanded by exactly one option at the upper or lower end of the price range. The prices and positions of all other options have to remain constant. Overall, we find nine such cases in our dataset. They comprise 16.8 percent of all observations in the data. In three cases, a low-price option is added, while in the other six cases a high-price option expands the category. We will compare the market shares of the option that becomes a compromise before and after the the menu change (i.e., the market share within the category).

For the pure cases we calculate the extent of the compromise effect according to our measures $\Delta P_{1}, \Delta P_{2}$, and $\Delta P_{3}$. To illustrate, consider the example from Figure 1 with quality as attribute 1 and inverse price as attribute 2. Suppose that in a particular category the original menu features four options. If a low-price option $v$ is added, the category in the old menu is given by $S=\{w, x, y, z\}$ (listed by price from the cheapest to the most expensive option), and by $T=\{v, w, z, y, z\}$ in the new menu. Option $w$ becomes a compromise so that our three measures are given by

$$
\begin{aligned}
\Delta P_{1}(w) & =P(w ; T)-P(w ; S), \\
\Delta P_{2}(w) & =P(w, z ; T)-P(w, z ; S), \\
\Delta P_{3}(w) & =P(w, S-w ; T)-P(w, S-w ; S) .
\end{aligned}
$$

Next, consider the case when a high-price option $z$ is added. Denote the category in the old menu by $S=\{v, w, x, y\}$, and in the new menu by $T=\{v, w, z, y, z\}$. Now option $y$ becomes a compromise and the three measures are given by

$$
\begin{aligned}
\Delta P_{1}(y) & =P(y ; T)-P(y ; S), \\
\Delta P_{2}(y) & =P(y, v ; T)-P(y, v ; S), \\
\Delta P_{3}(y) & =P(y, S-y ; T)-P(y, S-y ; S) .
\end{aligned}
$$

We implicitly assume that price and quality of the options in a category are positively related. A dish with a lower price must be of lower quality than a dish that exhibits a higher price. This assumption seems to be reasonable: According to the owner of the restaurant, the pricing is based on a cost-plus-markup method. Hence, more expensive ingredients as well as more sophisticated preparation - both being indicators of higher quality - determine higher prices. 


\subsection{Regression Analysis}

In this subsection, we outline our empirical strategy. We first estimate discrete choice conditional logit models. They allow us to control for alternative-specific and contextual factors which potentially influence customers' decisions so that we can use the entire dataset. Next, we depart from the IIA assumption and allow for correlated unobserved heterogeneity in a mixed logit framework. Finally, we apply an instrumental variable (IV) framework to address potential endogeneity issues, which may arise if the restaurant owner exploits the compromise effect.

\subsubsection{Conditional logit analysis}

We estimate conditional logit models to analyze the decision as a function of an item's position in the menu. ${ }^{10}$ Assume that, for individual $i$ and dish choice $k$, utility $U_{i k}$ is additively separable in a deterministic component $V_{i k}$ and a random component $\epsilon_{i k}$, which is an independently, identically distributed value:

$$
U_{i k}=V_{i k}+\epsilon_{i k} \quad \text { for all } \quad k=\{1, \ldots, K\} .
$$

In our data, we only observe the choice that yields the highest utility:

$$
\operatorname{Pr}\left(y_{i}=k\right)=\operatorname{Pr}\left(U_{i k} \geq U_{i l}\right)=\operatorname{Pr}\left(\epsilon_{i l}-\epsilon_{i k} \leq V_{i k}-V_{i l}\right) \quad \text { for all } \quad l \neq k \in K,
$$

where the deterministic part of this utility is explained by alternative specific regressors $\left(X_{i k}\right)$, such as price or position, and by case-specific regressors $\left(Z_{i}\right)$, such as the weather or the overall economic situation:

$$
V_{i k}=X_{i k}^{\prime} \beta+Z_{i}^{\prime} \gamma_{k}
$$

The covariate vector comprises an alternative-specific intercept that captures time-invariant, unexplained utility similar to a fixed effect. The probability of choosing $k$ conditional on all observables can then be written as:

$$
p_{i k}=\operatorname{Pr}\left(y_{i}=k \mid X_{i k}, \beta, Z_{i}, \gamma_{k}\right)=F_{k}\left(X_{i k}, \beta, Z_{i}, \gamma_{k}\right),
$$

and the individual likelihood contribution is given by

$$
L_{i}\left(y_{i} \mid X_{i k}, \beta, Z_{i}, \gamma_{k}\right)=\prod_{k=1}^{K} p_{i k} .
$$

Under the assumption that, conditional on the position in the menu and other observables, IIA holds, we can write the choice probability as:

$$
p_{i k}=\frac{\exp \left(X_{i k}^{\prime} \beta+Z_{i}^{\prime} \gamma_{k}\right)}{\sum_{l=1}^{L} \exp \left(X_{i l}^{\prime} \beta+Z_{i}^{\prime} \gamma_{l}\right)} .
$$

\footnotetext{
${ }^{10}$ See, for example, Train (2003) or Cameron and Trivedi (2009) for a description of conditional logit models.
} 
The alternative-specific intercepts reflect the desirability of each alternative according to its unmeasured time-invariant attributes. The interpretation of the coefficients of alternative-specific regressors is as follows: A positive coefficient means that if the respective regressor increases for one of the options, this item is chosen more often and all other items together are chosen less often. The case-specific regressors can be interpreted as parameters of a binary logit model against the base alternative. Relative to the probability of the base alternative, an increase of the regressor leads to an increase in the choice probability of the alternative if the respective coefficient has a positive sign. We compute marginal effects at the means of the explanatory variables for all price and position coefficients to quantify how the probability of choosing a certain item changes in response to a change in price or position. In particular, we are interested in comparing the marginal effect of moving an item to an extreme position to the marginal effect of a change in price.

We apply the conditional logit model to (i) the nine pure cases, (ii) all menu choices within each of the six categories. Using only the pure cases, we investigate how an individual's utility from a certain choice is influenced by the addition of a new extreme-position option. The introduction of this item is captured by a dummy indicating a change of menus. Hence, the utility specification for each of the nine pure cases is given by

$$
U_{i k}=\beta_{0}+\beta_{1} \text { price }_{i k}+\gamma_{1 k} \text { menu } \text { change }_{i}+Z_{i}^{\prime} \gamma_{k}+\epsilon_{i k}
$$

Since the pure cases comprise only a small fraction of the dataset, we run additional regressions in order to exploit all menu changes, even if they imply multiple modifications of the choice sets. To this end, we coded several alternative-specific dummy variables, indicating the location of an alternative within the respective category. In particular, we are interested in the coefficients of the following explanatory variables: first position within category, last position within category, and median position within category. If there is a compromise effect, all signs except for the one of median position within category should be negative. The utility specification for the models that exploit all menu changes equals

$$
U_{i k}=\beta_{0}+\beta_{1} \text { price }_{i k}+\beta_{2} \text { position }_{i k}+Z_{i}^{\prime} \gamma_{k}+\epsilon_{i k} .
$$

First, we estimate conditional logit models for all menu categories separately. This allows us to investigate whether the compromise effect is present in each menu category, and whether there exists heterogeneity in the effect, e.g., if it is larger for more extravagant food categories such as fish. Next, we use a random draw of the complete menu choices. ${ }^{11}$ In this way, we can control for the possibility that changing the choice set within a certain category may lead customers to switch to a different category of main dishes.

\footnotetext{
${ }^{11}$ Due to computational restrictions, we reduce the sample size by randomly drawing a subsample of observations. With 75 alternatives in the full menu sample, the simulations are computationally infeasible otherwise. In both steps, we have to estimate the models using an unbalanced choice set, as the number of available alternatives varies across individual observations.
} 


\subsubsection{Relaxing the IIA assumption}

The conditional logit estimator relies on the assumption that, conditional on observables, adding another non-preferred option or changing the characteristics of a non-preferred option does not affect the relative choice probabilities of two existing options. This assumption may not always be satisfied. As a robustness check, we therefore estimate mixed logits using maximum likelihood on the complete dataset. This allows us to introduce random taste variation, unrestricted substitution patterns, and correlation in unobserved factors. Most importantly, the mixed logit specification relaxes IIA by introducing normally distributed coefficients on price and/or item position, i.e., $\beta_{i}=\beta+v_{i}$ with $v_{i} \sim N\left(\mathbf{0}, \Sigma_{\beta}\right)$ (there can be an error correlation across choices). Conditional on the unobservable random part $v_{i}$, choice probabilities are then given by

$$
p_{i k} \mid v_{i}=\frac{\exp \left(X_{i k}^{\prime} \beta+X_{i k}^{\prime} v_{i}+Z_{i}^{\prime} \gamma_{k}\right)}{\sum_{l=1}^{L} \exp \left(X_{i l}^{\prime} \beta+X_{i l}^{\prime} v_{i}+Z_{i}^{\prime} \gamma_{l}\right)}
$$

The unobserved component $v_{i}$ is integrated out by numerical simulation using a sequence of Halton draws to simulate the probabilities.

\subsubsection{Addressing potential endogeneity}

Although the restaurant owner told us that prices were based on a cost-plus-markup calculation and that he was unaware of the compromise effect, we cannot rule out completely that he has implicitly or unconsciously taken advantage of the compromise effect when designing the menu. For example, he might have placed the previously most profitable dish in a middle position of the corresponding category (and change prices accordingly). ${ }^{12}$ Thus, demand for an item may depend on option characteristics, which are unobservable to the econometrician, but known to the restaurant owner, who takes them into account when determining an item's position on the menu. Denote by $\xi_{k m}$ such unobserved attributes for option $k$ in menu period $m$. The utility of individual $i$ from consuming option $k$ in menu period $m$ is then given by

$$
U_{i k m}=V\left(X_{k m}, Z_{i}, \beta, \gamma_{k}, v_{i}\right)+\xi_{k m}+\epsilon_{i k m}
$$

where $X_{k m}$ comprises price and position variables. The position variables are endogenous with respect to the information contained in $\xi_{k m}$, resulting in biased coefficient estimates. We address this concern in two steps. First, we estimate panel data fixed effects models with position variables on the left hand side and lagged market shares from the previous menu period on the right hand side, to see if the current position in the menu correlates with past demand. Second, we estimate the parameters of a random-coefficients logit demand model from product market shares using the Berry-Levinsohn-Pakes estimator (Berry et al. 1995, henceforth BLP). ${ }^{13}$ The idea of this estimator

\footnotetext{
${ }^{12}$ We are grateful to one anonymous reviewer for pointing this problem out to us.

${ }^{13}$ Each menu period constitutes a "market" (in BLP-speak) in our application. Note that market shares can be computed from individual choices, because our data contain the universe of restaurant purchases of the sample period.
} 
is to make the unobserved part of utility $\xi_{k m}$ observable by estimating constants, $\delta_{k m}$, for each dish in each menu period. These constants subsume the part of the utility function that varies only by choice and menu period, $\delta_{k m}=X_{i k}^{\prime} \beta+\xi_{k m} \cdot{ }^{14}$ In this way, all endogeneity is taken out of the choice equations. The estimated constants can then be used within an instrumental variable (IV) framework to obtain causal estimates of the corresponding $\beta \mathrm{s}$, where the position variables are instrumented by variables that satisfy the IV assumptions. The instruments need to correlate strongly with the position variables and need to influence the choice utility only via their influence on the position variables. We identify indicators of seasonality and past position indicators as suitable instruments. Seasonality - as measured by the average outside temperature - is a good instrument in our application, because menus tend to change as seasons change (due to the availability of ingredients and because dishes tend to be lighter in the summer than in the winter). Past position indicators are good instruments because the menus were never designed from scratch, so past dish positions in the menu strongly predict current positions. At the same time, past positions should not influence current customer choices other than through their impact on the current position.

A final remark concerns the potential endogeneity of the price variable. In some applications of structural demand analysis, it is necessary to instrument prices. We think that this is not necessary in our case, for the following reasons. First, in our application, the price serves as a control variable only, and we are not interested in causal effect of prices on customer demand. Second, the restaurant mostly serves walk-in customers. The number of regular customers, who may think that their demand influences the composition of menus, is small. Third, prices are calculated based on a cost-plus-markup method. Cost changes result from a change in input prices and thus are independent of customer choice.

\section{Results}

\subsection{Evidence from the Quasi-Experimental Cases}

We first examine the part of the data that is closest to an experimental setting, namely the nine pure cases. Table 3 shows for each pure case the market share of each dish on the original menu (denoted by $S$ ) and the extended menu (denoted by $T$ ), as well as the three descriptive compromise effect measures. The market shares of the compromise options are printed in bold letters. We observe that the differences in absolute market shares $\Delta P_{1}$ are positive in eight out of nine cases. However, they are small - between 0.92 and 5.12 percentage points - so that only two differences are significant.

[Insert Tables 3 and 4 about here]

Turning to the change in the market share relative to the most extreme alternative option in the original menu, $\Delta P_{2}$, we find positive differences in all cases except one. Five differences are

\footnotetext{
${ }^{14}$ The number of constants is potentially very large. To deal with the problem that each iteration requires a large number of constants, we use the contraction proposed by BLP and implemented by Vincent (2015), which uses the fact that predicted shares in each menu period should equal actual shares.
} 
significantly positive, and the positive differences vary between 2.80 and 30.54 percentage points. The least conservative measure for the compromise effect, $\Delta P_{3}$, turns out to be significantly positive in six cases, with positive differences between 2.10 and 22.69 percentage points. Overall, there is substantial evidence for the compromise effect.

Two other issues are worth noticing. First, the compromise effect is more pronounced in the categories with relatively few items (Cases 5, 6 and 7, each having four options in the original menu). This result is consistent with previous experimental findings (see Kivetz et al. 2004a). Second, in each of the nine cases, the option that is a direct compromise in the original menu, but moves more into the middle in the extended menu (e.g., option $w$ in Case 1) loses market shares. The probability of this item being chosen decreases by around 5 percentage points and the corresponding coefficient is significant at the 5 -percent level in 5 out of 9 cases (detailed calculations not shown). This provides further evidence that the compromise effect matters in our setting.

Table 4 shows the results of conditional logit regressions for each of the quasi-experimental cases. The upper panel displays the regressions without controls; the lower panel shows the regressions including a number of important covariates. The average marginal effect displayed refers to the coefficient of the compromising choice option. The compromise effect implies a positive sign. In line with the descriptives reported in Table 3, we find evidence for a compromise effect. However, only the coefficients for cases with smaller choice sets are significantly positive.

\subsection{Complete Sample Evidence}

We now consider the regression results for the complete dataset. We start out by presenting categorywise conditional logit estimations and then turn to the conditional logit estimations over all alternatives. We then proceed by relaxing the IIA assumption in mixed logit models. Last, we address potential endogeneity and investigate the existence group size effect.

\subsubsection{Conditional logit analysis}

Tables 5 to 10 display the marginal effects that correspond to the category-wise conditional logit specifications. ${ }^{15}$ The marginal effects displayed in those tables have been transformed so that they can be interpreted as percentage (instead of percentage point) changes in the demand for each item in response to being moved to an extreme or median position. Thus, all marginal effects have been adjusted for the fact that different dishes are chosen with different baseline probabilities. In order to compare the estimated compromise effect to a change in prices, the footnotes of the tables report own-price marginal effects (in percentage terms) of a one Euro increase in the price of the respective dish.

[Insert Tables 5 to 10 about here]

\footnotetext{
${ }^{15}$ The corresponding coefficients are displayed in Tables B.1 to B.6 of the Online Appendix.
} 
Being placed in an extreme position within a certain category mostly decreases the choice probability of an option; in contrast, being placed in the median position increases it in all cases. ${ }^{16}$ There is evidence for the compromise effect in all categories, yet there are some important exceptions. First, being in first position (low-price, low-quality item) has a significantly positive impact on the probability of being chosen in category 3 (venison). A possible explanation for this exception might be the overall price level in this category. As can be seen in Table 2, venison is the menu category with the highest average price level. ${ }^{17}$ Customers may pick the lowest price alternative, because they know that it is still a medium-price, medium-quality option when compared to the complete menu.

Second, regarding the last position, positive signs are found for category 1 (traditional dishes) and category 6 (vegetarian). ${ }^{18}$ Again, the overall price level in these categories might explain this finding, given that categories 1 and 6 are the lowest price categories in the overall menu (see Table 2). Hence, customers might be willing to select the highest price/quality alternative in an otherwise cheap category.

The size of the estimated compromise effect again differs between categories. It seems to be most pronounced in categories which contain expensive high quality foods such as fish or steaks (categories 2 and 4) and least pronounced in categories which contain familiar, inexpensive foods such as traditional or vegetarian dishes (categories 1 and 5). This confirms the findings from Sheng et al. (2005) who show that familiarity with the choice set weakens the compromise effect. When comparing the compromise effect to the marginal effect of a one Euro increase in an item's price, we find that the compromise effect is often twice as large. ${ }^{19}$ However, there is again much heterogeneity, with the estimated price effect being 0.2 to 2 times as large as the estimated compromise effect. Overall, the category-wise regressions support the evidence found in the nine pure cases. A compromise effect seems to be present in all of the categories, while the magnitude of the effect varies in the food category.

\section{[Insert Tables 11 to 13 about here]}

Next, we estimate a set of full menu conditional logit models. There are 75 different options that were offered over the course of the observation period. About a third of them was listed in each menu. Hence, we use an unbalanced choice set in the estimations. In order to keep running

\footnotetext{
${ }^{16}$ All dishes are listed according to price within each of the categories. In the part of the analysis where we examine the categories separately, we can therefore only investigate whether there exists a compromise effect above and beyond the (linear) price effect.

${ }^{17}$ We also tested for the influence of category-wise price levels on consumer choices using a two-level nested logit model with prices as explanatory variable on the first-level. Category price coefficients were not significant. This indicates that the beliefs of customers about the average price of a respective category are fixed and not updated at every restaurant visit.

${ }^{18} \mathrm{An}$ initial hypothesis that the large variety in dishes subsumed under categories 1 and 6 would explain this anomaly was not confirmed in robustness checks. Specifically, controlling for whether an item was a soup or a homemade roast did not affect our results. In addition, Table B.7 of the Online Appendix shows that our results are robust to the inclusion of a monthly time trend.

${ }^{19}$ In a linear model this would imply that putting an item first or last in a category reduced demand by about as much as a 2 Euro increase in price.
} 
times for the computations tractable, we included only alternative-specific constants and number of main dishes on the bill as controls. Table 11 displays the estimated marginal effects and Table 13 displays the corresponding coefficient estimates. We find a significant effect of around 20 percent for the last position within category. Hence, if a dish is the highest-price, highest-quality option of a category, this reduces its choice probability considerably and about as much as a one Euro increase in prices. In contrast, being the lowest-price, lowest-quality option as well as being placed in a middle position does not have a significant impact on the market share.

\subsubsection{Relaxing the IIA assumption}

The previous analysis assumes separability in the utility function across choices and categories. This assumption might not always be satisfied. As a robustness check we estimate a set of mixed logit models with random coefficients on all price and position variables. This allows us to relax IIA by introducing correlation in unobserved factors across choices. The results for the full set of menu choices are displayed in Table $14 .^{20}$ We find that the coefficient on the last position regressor of the mixed logits has a standard deviation that is significantly different from zero. However, comparing likelihood values and information criteria displayed in Tables 13 and 14 reveals that the mixed logit model does not provide a significantly better fit to the data. Regarding the size and significance of the coefficients, we find that the compromise effect for the last position is more pronounced in the mixed logit model. Otherwise, the results are very similar. ${ }^{21}$

\section{[Insert Table 14 about here]}

\subsubsection{Addressing potential endogeneity}

So far, we have treated an option's menu position as an exogenous variable. However, this assumption may be violated, for example, if the restaurant owner takes advantage of the compromise effect when designing the menu. ${ }^{22}$ To accommodate such concerns, we investigate whether an item's position in the current menu is significantly related to its popularity in past menu periods. We collapse all our data to a panel with 21 menu periods and a number of up to 75 dishes per menu period. ${ }^{23}$ This data structure allows us to investigate, for example, whether a certain dish gets moved to the middle of a category if it generated a lot of revenue during the last menu period.

We estimate dish-fixed effects regressions with position variables on the left hand side and with lagged revenue per month (in logs) and price variables on the right hand side. ${ }^{24}$ Lagged prices need

\footnotetext{
${ }^{20}$ Results of mixed logit models for each of the categories can be found in Tables C.1 to C.6 of the Online Appendix.

${ }^{21}$ Given the enormous size of our dataset, the estimation of the mixed logit models is computationally very demanding. Marginal effects with the corresponding standard errors could therefore not be obtained for this class of models.

${ }^{22}$ Another concern might be that more (or fewer) items are placed in a category to increase or decrease the attention of customers. We investigate this in Table D.1 of the Online Appendix and find no evidence supporting this hypothesis.

${ }^{23}$ Dishes varied over menu periods, such that this yields an unbalanced panel.

${ }^{24}$ Note that we lose the first menu period by introducing lagged explanatory variables. This reduces the number of menu periods to 20 .
} 
to be accounted for in this analysis, because prices and positions are closely linked in the way the menu is set up (by ascending order of price). After conditioning on the price, revenue is informative of a dish's popularity, i.e., it indicates how many times a certain item has been chosen while keeping prices constant. Table 15 displays the results of this exercise. It shows that a one hundred Euro increase in revenue per month (starting at the average of 385 Euro) generated by a certain dish over the last menu period is not significantly correlated with extreme positions in the current menu. Moreover, the estimated coefficients are rather small. Only with respect to the median position we do find that a one hundred Euro increase in revenue is associated with a 2 to 4 percent increase in the probability that the dish can be found in a median position with a coefficient that is close to significant at the 10-percent level in the balanced panel.

[Insert Tables 15 to 17 about here]

We thus proceed with an instrumental variable strategy as described in the last part of Section 3. Specifically, we follow the strategy proposed by BLP using overall market shares as dependent variables and temperatures as well as past position variables as instruments for the estimated constants. To construct market shares, we use the universe of restaurant purchases over each of the menu periods. For each of the 21 menu periods $m$, we observe nine dishes continuously. Adding one outside option per category and period and dropping the first menu period, due to the use of lagged variables as instruments, leaves us with 300 observations. ${ }^{25}$ We then employ the BLP estimation strategy in a model with covariates that comprise item prices and position variables where the position variables are instrumented with the average outside temperature over the current menu period and position indicators from the previous menu period. Moreover, we introduce individual unobserved heterogeneity in the price coefficients to allow for correlated errors across choices.

Past menu position indicators are valid instruments for the position in the current menu as they do not influence current customer choices except through their influence on the current position. To evaluate their strength, Table 16 presents the first stage estimation results. We find that the current position of an item in the menu is strongly predicted by its past position with adjusted R-squares above 60 percent and F-statistics strongly exceeding 100.

The results of the causal BLP models are presented in Table 17. Our estimates strongly support the hypothesis of a compromise effect. If a dish is listed first or last within a category, this has a strong negative effect on choice utility (columns 1 and 2). On the contrary, being listed at the medium position yields a strong positive effect (columns 3 and 4). All estimated effects are highly significant at the 1-percent level and the estimated coefficients are robust to the inclusion of additional covariates such as the average business climate or the average number of dishes on the bill in a menu period. ${ }^{26}$

\footnotetext{
${ }^{25}$ Constructing such an outside option is necessary to obtain a complete set of market shares and because much of the variability in the data stems from exactly those options that are added to or deleted from the menu over time.

${ }^{26}$ We could also include evening or weekend indicators in the set of control variables, but those hardly vary across menu periods.
} 


\subsubsection{Group size effects}

We conclude the analysis by investigating whether the compromise effect varies across group size. Communication between customers may weaken the compromise effect (Simonson and Nowalis 2000, Chuang et al. 2012). To investigate this hypothesis, we split our data by the number of main dishes per bill and then rerun the conditional logit regressions and the BLP analysis. Table 18 displays the conditional logit results for single dish bills (columns 1 and 2) and for bills with more than one main dish (columns 3 and 4). We find that the compromise effect for the last position is significant only if individuals dine in groups. Similarly, the analysis that uses the BLP estimator indicates that the compromise effect is pronounced when customers dine in groups. ${ }^{27}$ We proceed by investigating whether the results differ for other group size cutoffs and for large groups of more than four individuals (results not displayed), but we do not find any differences in the position coefficients with respect to an analysis that comprises all bills with 2,3 or 4 main dishes. ${ }^{28}$

[Insert Table 18 about here]

This subgroup analysis, however, comes with three caveats. First, given our data, we cannot investigate whether individuals who dine alone are systematically different from individuals who eat and pay in groups. In fact, individuals who go to a restaurant by themselves might (almost by definition) be less sensitive to compromise effects. Second, while coefficients are insignificant in the analysis of the single main dish bills, the point estimates are far from zero and the effects are less precisely estimated due to the smaller sample size. Third, we do not observe actual group size, but only the number of main dishes per bill. Hence, some of the single eaters in our data might in fact have eaten in groups with separate bills per person.

\section{Conclusion}

This paper provides evidence for the compromise effect in a real-world choice situation. Using a dataset of individual choices at a specialties restaurant, we find that the market share of an extreme option increases on average by five percentage points if it becomes a compromise option. The strength of the effect, however, varies substantially between product categories. The effect is most pronounced in categories which contain expensive, high quality foods and least pronounced in categories which contain inexpensive, familiar items. Moreover, we find that the size of a consumer group may change the magnitude of the compromise effect. While choices by groups exhibit a significant compromise effect, it becomes statistically insignificant for single individuals.

These results validate a large literature that analyzes the scope and magnitude of the compromise effect using hypothetical choice experiments. Specifically, they show that the compromise effect

\footnotetext{
${ }^{27}$ See Tables E.1 and E.2 of the Online Appendix.

${ }^{28}$ We find insignificant or even positive coefficient on the price variable for singles and for very large groups, which may imply that individuals choose more expensive items when they are by themselves or if they can hide in a group whilst being sure that someone else will pay the bill. Similarly, the compromise effect tends to vanish in very large groups of more than 12 individuals. These groups however make up for a very small part of the sample $(<0.3 \%)$, such that we cannot derive robust conclusions for them.
} 
may arise in environments that exhibit many features which potentially reduce the strength of the compromise effect, i.e., a large choice set, decision makers who are familiar with the choice situation and (most likely) also with some options from the choice set, as well as the opportunity of communication between customers to discuss or recommend choices.

Practitioners and marketers can take advantage of these results by appropriately designing choice menus. This seems to be especially relevant for menus in which a large set of options is organized in several sub-categories (as is common in restaurants) and consumers have to weigh alternatives with respect to several attributes. There are plenty of examples outside of gastronomy where this is the case, e.g., internet commerce, trade of complex goods (such as cars) with many optional addons, voting in political elections, or Likert scales in surveys. In particular, the availability of large datasets on consumer choices will allow firms to fine-tune their strategies to exploit the compromise effect in the future. 


\section{References}

Abeler, J., Marklein, F., forthcoming. Fungibility, Labels, and Consumption. Journal of the European Economic Association.

Apesteguia, J., Ballester, M., 2013. Choice by sequential procedures. Games and Economic Behavior $77(1), 90-99$.

Berry, S., Levinsohn, J., Pakes, A., 1995. Automobile prices in market equilibrium. Econometrica $63(4), 841-890$.

Cameron, A. C., Trivedi, P. K., 2009. Microeconomics Using Stata. Stata Press.

Chuang, S.-C., Cheng, Y.-H., Hsu, C.-T., 2012. The influence of suggestions of reference groups in the compromise effect. Journal of Economic Psychology 33(3), 554-565.

De Clippel, G., Eliaz, K., 2012. Reason-based Choice: A Bargaining Rationale for the Attraction and Compromise Effects. Theoretical Economics 7(1), 125-162.

Dhar, R., Nowlis, S. M., Sherman, S. J., 2000. Trying hard or hardly trying: An analysis of context effects in choice. Journal of Consumer Psychology 9(4), 189-200.

Dhar, R., Simonson, I., 2003. The Effect of Forced Choice on Choice. Journal of Marketing Research 40(2), 146-160.

DellaVigna, S., 2009. Psychology and Economics: Evidence from the Field. Journal of Economic Literature 47(2), 315-372.

DellaVigna, S., Malmendier, U., 2006. Paying Not to Go to the Gym. American Economic Review 96(3), 694-719.

Doyle, J. R., O’Connor, D. J., Reynolds, G. M., Bottomley, P. A., 1999. The robustness of the asymmetrically dominated effect: Buying frames, phantom alternatives, and in-store purchases. Psychology and Marketing 16(3), 225-243.

Ehlers, L., Sprumont, Y., 2008. Weakened WARP and top-cycle choice rules. Journal of Mathematical Economics 44(1), 87-94.

Iyengar, S. S., Lepper, M. R., 2000. When choice is demotivating: Can one desire too much of a good thing? Journal of Personality and Social Psychology 79(6), 995-1006.

Kamenica, E., 2008. Contextual Inference in Markets: On the Informational Content of Product Lines. American Economic Review 98(5), 2127-2149.

Kivetz, R., Netzer, O., Srinivasan, V., 2004a. Alternative models for capturing the compromise effect. Journal of Marketing Research 41(3), 237-257. 
Kivetz, R., Netzer, O., Srinivasan, V., 2004b. Extending compromise effect models to complex buying situations and other context effects. Journal of Marketing Research 41(3), 262-268.

Levitt, S., List, J. A., 2007. Viewpoint: On the generalizability of lab behaviour to the field. Canadian Journal of Economics 40(2), 347-370.

List, J., Rasul, I., 2010. Field Experiments in Labor Economics. In D. Card and O. Ashenfelter (eds): Handbook of Labor Economics (Vol. 4a), Amsterdam, North Holland.

Lombardi, M., 2008. Uncovered set choice rules. Social Choice and Welfare 31(2), 271-279.

Manzini, P., Mariotti, M., 2007. Sequentially Rationalizable Choice. American Economic Review $97(5), 1824-1839$.

Masatlioglu, Y., Ok, E., 2005. Rational choice with status quo bias. Journal of Economic Theory $121(1), 1-29$.

Prelec, D., Wernerfelt, B., Zettelmeyer, F., 1997. The Role of Inference in Context Effects: Inferring What You Want from What is Available. Journal of Consumer Research 24(1), 118-125.

Rubinstein, A., Salant, Y., 2006. A model of choice from lists. Theoretical Economics 1(1), 3-17.

Salant, Y., Rubinstein, A., 2008. $(A, f)$ : Choice with Frames. Review of Economic Studies 75(4), $1287-1296$.

Sheng, S., Parker, A. M., Nakamoto, K., 2005. Understanding the mechanism and determinants of compromise effects. Psychology and Marketing 22(7), 591-609.

Simonson, I., 1989. Choice Based on Reasons: The Case of Attraction and Compromise Effects. Journal of Consumer Research 16(2), 158-174.

Simonson, I., Tversky, A., 1992. Choice in Context: Tradeoff Contrast and Extremeness Aversion. Journal of Marketing Research 29(3), 281-295.

Simonson, I., Nowlis, S. M., 2000. The role of explanations and need for uniqueness in consumer decision making: Unconventional choices based on reasons. Journal of Consumer Research 27(1), 49-68.

Train, K., 2003. Discrete choice methods with simulation. Cambridge University Press, New York.

Tversky, A., Simonson, I., 1993. Context-Dependent Preferences. Management Science 39(10), 11791189.

Vincent, D. W., 2015. The Berry-Levinsohn-Pakes estimator of the random-coefficients logit demand model. Stata Journal 15(3), 854-880.

Wernerfelt, B., 1995. A rational reconstruction of the compromise effect: Using market data to infer utilities. Journal of Consumer Research 21(4), 627-633. 


\section{Tables}

Table 1: Summary statistics of the main explanatory variables

\begin{tabular}{lcccc}
\hline \hline \multicolumn{1}{c}{ Variable } & Mean & Std. Dev. & Min. & Max. \\
\hline price of item in EUR (per unit) & 10.05 & 2.63 & 3.5 & 17.8 \\
number of dishes in category & 4.92 & 1.44 & 2 & 8 \\
first position within category & 0.23 & 0.42 & 0 & 1 \\
last position within category & 0.22 & 0.42 & 0 & 1 \\
median position within category & 0.38 & 0.49 & 0 & 1 \\
number of main dishes on the bill & 3.62 & 2.24 & 1 & 15 \\
outside table & 0.29 & 0.46 & 0 & 1 \\
monthly business climate & 96.69 & 7.04 & 82.3 & 108.9 \\
evening order & 0.28 & 0.45 & 0 & 1 \\
public holiday & 0.05 & 0.22 & 0 & 1 \\
weekend & 0.57 & 0.49 & 0 & 1 \\
\hline \multicolumn{5}{c}{$\mathrm{N}$} \\
\hline \hline
\end{tabular}

Notes: The table displays means and standard deviations of the main explanatory variables. Outside table indicates whether a table is located in the outside area of the restaurant. Monthly business climate refers to the CESifo monthly business cycle indicator. Evening order indicates whether a dish was ordered after 5pm. Public holiday indicates whether a dish was ordered on a public holiday. Weekend indicates whether a dish was ordered on a weekend.

Table 2: Summary statistics by category

\begin{tabular}{|c|c|c|c|c|c|c|c|c|c|c|c|}
\hline & \multirow[b]{2}{*}{$\mathrm{N}$} & \multicolumn{2}{|c|}{ random shares } & \multicolumn{2}{|c|}{ price } & \multicolumn{2}{|c|}{ first position } & \multicolumn{2}{|c|}{ last position } & \multicolumn{2}{|c|}{ median position } \\
\hline & & All & Median & Mean & StdDev & Mean & StdDev & Mean & StdDev & Mean & StdDev \\
\hline traditional & 24,689 & 0.15 & 0.22 & 8.85 & 2.01 & 0.14 & 0.35 & 0.31 & 0.46 & 0.25 & 0.43 \\
\hline fish & 13,568 & 0.21 & 0.31 & 11.07 & 1.64 & 0.19 & 0.40 & 0.18 & 0.38 & 0.37 & 0.48 \\
\hline venison & 13,763 & 0.24 & 0.43 & 12.95 & 1.82 & 0.25 & 0.43 & 0.16 & 0.37 & 0.54 & 0.50 \\
\hline steak & 19,402 & 0.21 & 0.35 & 10.75 & 1.58 & 0.23 & 0.42 & 0.19 & 0.39 & 0.44 & 0.50 \\
\hline poultry & 7,436 & 0.29 & 0.42 & 9.51 & 2.34 & 0.32 & 0.47 & 0.26 & 0.44 & 0.50 & 0.50 \\
\hline vegetarian & 9,255 & 0.22 & 0.33 & 6.36 & 2.00 & 0.42 & 0.49 & 0.17 & 0.38 & 0.28 & 0.45 \\
\hline
\end{tabular}

Notes: The table displays means and standard deviations of the position variables by category. Random share (All) refers to the share of dishes that would have been ordered at random, as defined by one divided by the average total number of dishes per category. Random share (Median) refers to the share of median dishes that would have been ordered if preferences were random. The middle position is defined such that it equals the median whenever there is an unequal number of items. When there is an equal number of items within a category, the two middle items are both defined to be at the median position within the category. 
Table 3: Absolute market shares and descriptive compromise effect measures $\Delta P_{1}, \Delta P_{2}$ and $\Delta P_{3}$

\begin{tabular}{ccccccccc}
\hline \hline & \multicolumn{2}{c}{ Case 1} & \multicolumn{9}{c}{ Case 2} \\
\hline Position & Menu $S$ & Menu $T$ & Position & Menu $S$ & Menu $T$ & Position & Menu $S$ & Menu $T$ \\
u & & 12.03 & u & 8.68 & 6.47 & v & & 11.09 \\
v & $\mathbf{7 . 6 5}$ & $\mathbf{8 . 5 8}$ & v & 37.19 & 33.81 & w & $\mathbf{2 3 . 7 1}$ & $\mathbf{2 5 . 5 0}$ \\
w & 22.06 & 15.08 & w & 28.51 & 20.14 & x & 38.26 & 26.16 \\
x & 28.83 & 25.73 & x & 7.02 & 6.47 & y & 19.69 & 23.01 \\
y & 15.66 & 15.35 & y & $\mathbf{1 8 . 6 0}$ & $\mathbf{2 0 . 1 4}$ & z & 18.34 & 14.24 \\
z & 25.80 & 23.24 & z & & 12.95 & & &
\end{tabular}

$\begin{array}{llllllll}\text { N obs. } & 562 & 723 & \text { N obs. } & 242 & 139 & \text { N obs. } & 447\end{array}$

Pearson $\operatorname{chi} 2(5)=1.2 \mathrm{e}+03 \operatorname{Pr}=0.000 \quad$ Pearson $\operatorname{chi} 2(5)=173.7027 \operatorname{Pr}=0.000 \quad$ Pearson $\operatorname{chi} 2(4)=437.1481 \operatorname{Pr}=0.000$

\begin{tabular}{|c|c|c|c|c|c|c|c|c|}
\hline & \multicolumn{2}{|c|}{$\begin{array}{l}\Delta P_{1}(v)=0.92 \\
\Delta P_{2}(v)=4.08 \\
\Delta P_{3}(v)=2.10\end{array}$} & \multicolumn{3}{|c|}{$\begin{array}{l}\Delta P_{1}(y)=1.55 \\
\Delta P_{2}(y)=7.49 \\
\Delta P_{3}(y)=4.55\end{array}$} & \multicolumn{3}{|c|}{$\begin{array}{c}\Delta P_{1}(w)=1.78 \\
\Delta P_{2}(w)=7.78^{*} \\
\Delta P_{3}(w)=4.96^{* *}\end{array}$} \\
\hline \multicolumn{3}{|c|}{ Case 4} & \multicolumn{3}{|c|}{ Case 5} & \multicolumn{3}{|c|}{ Case 6} \\
\hline $\begin{array}{c}\text { Position } \\
\mathrm{v}\end{array}$ & Menu $S$ & $\begin{array}{c}\text { Menu } T \\
13.38\end{array}$ & $\begin{array}{c}\text { Position } \\
\text { w }\end{array}$ & $\begin{array}{c}\text { Menu } S \\
26.66\end{array}$ & $\begin{array}{c}\text { Menu } T \\
24.84\end{array}$ & $\begin{array}{c}\text { Position } \\
\text { w }\end{array}$ & $\begin{array}{c}\text { Menu } S \\
25.00\end{array}$ & $\begin{array}{c}\text { Menu } T \\
8.54\end{array}$ \\
\hline $\mathrm{w}$ & 20.82 & 16.56 & $\mathrm{x}$ & 46.26 & 36.87 & $\mathrm{x}$ & 55.73 & 25.20 \\
\hline $\mathrm{x}$ & 32.39 & 30.57 & $\mathrm{y}$ & 27.08 & 28.77 & $\mathrm{y}$ & 19.27 & 24.39 \\
\hline $\mathrm{y}$ & 30.85 & 28.03 & z & & 9.52 & $\mathrm{z}$ & & 41.87 \\
\hline z & 15.94 & 11.46 & & & & & & \\
\hline $\begin{array}{l}\mathrm{N} \text { obs. } \\
\text { Pearson }\end{array}$ & $\begin{array}{c}389 \\
\text { hi2 } 2(4)=\end{array}$ & $\begin{array}{c}157 \\
38 \mathrm{Pr}=0\end{array}$ & $\begin{array}{l}\text { N obs. } \\
\text { Pearson }\end{array}$ & $\begin{array}{c}4,265 \\
\operatorname{chi} 2(3)=\end{array}$ & $\begin{array}{c}5,367 \\
03 \mathrm{Pr}=0\end{array}$ & $\begin{array}{l}\mathrm{N} \text { obs. } \\
\text { Pearson }\end{array}$ & $\begin{array}{c}192 \\
\operatorname{hi} 2(3)=\end{array}$ & $\begin{array}{c}492 \\
654 \operatorname{Pr}=\end{array}$ \\
\hline
\end{tabular}

\begin{tabular}{|c|c|c|c|c|c|c|c|c|}
\hline \multicolumn{3}{|c|}{$\begin{array}{l}\Delta P_{1}(w)=-4.26 \\
\Delta P_{2}(w)=-2.45 \\
\Delta P_{3}(w)=-1.70 \\
\end{array}$} & \multicolumn{3}{|c|}{$\begin{array}{l}\Delta P_{1}(y)=1.69^{* *} \\
\Delta P_{2}(y)=3.27^{* * *} \\
\Delta P_{3}(y)=4.71^{* * *}\end{array}$} & \multicolumn{3}{|c|}{$\begin{array}{c}\Delta P_{1}(y)=5.12^{*} \\
\Delta P_{2}(y)=30.54^{* * *} \\
\Delta P_{3}(y)=22.69^{* * *}\end{array}$} \\
\hline \multicolumn{3}{|c|}{ Case 7} & \multicolumn{3}{|c|}{ Case 8} & \multicolumn{3}{|c|}{ Case 9} \\
\hline Position & Menu $S$ & Menu $T$ & Position & Menu $S$ & Menu $T$ & Position & Menu $S$ & Menu $T$ \\
\hline w & 27.68 & 17.20 & $\mathrm{v}$ & 45.00 & 48.06 & $\mathrm{u}$ & 44.79 & 36.71 \\
\hline $\mathrm{x}$ & 50.87 & 38.53 & $\mathrm{w}$ & 16.50 & 17.95 & $\mathrm{v}$ & 17.35 & 17.72 \\
\hline $\mathrm{y}$ & 21.45 & 23.39 & $\mathrm{x}$ & 28.50 & 10.17 & $\mathrm{w}$ & 13.88 & 12.03 \\
\hline \multirow[t]{3}{*}{ z } & & 20.87 & $\mathrm{y}$ & 10.00 & 12.76 & $\mathrm{x}$ & 12.62 & 5.70 \\
\hline & & & z & & 11.07 & $\mathrm{y}$ & 11.36 & 14.56 \\
\hline & & & & & & $\mathrm{z}$ & & 13.29 \\
\hline N obs. & 289 & 436 & N obs. & 200 & 1,003 & N obs. & 317 & 158 \\
\hline \multicolumn{3}{|c|}{ Pearson chi2 $(3)=226.8622 \operatorname{Pr}=0.000$} & Pearson & $\operatorname{chi} 2(4)=$ & $349 \operatorname{Pr}=0.000$ & \multicolumn{3}{|c|}{ Pearson $\operatorname{chi} 2(5)=249.0974 \operatorname{Pr}=0.000$} \\
\hline \multirow{3}{*}{\multicolumn{3}{|c|}{$\begin{array}{c}\Delta P_{1}(y)=1.94 \\
\Delta P_{2}(y)=13.97^{* * *} \\
\Delta P_{3}(y)=8.11^{* *}\end{array}$}} & \multicolumn{3}{|c|}{$\Delta P_{1}(y)=2.76$} & \multicolumn{3}{|c|}{$\Delta P_{1}(y)=3.20$} \\
\hline & & & \multicolumn{3}{|c|}{$\Delta P_{2}(y)=2.80$} & \multicolumn{3}{|c|}{$\Delta P_{2}(y)=8.17^{*}$} \\
\hline & & & \multicolumn{3}{|c|}{$\Delta P_{3}(y)=4.35^{*}$} & \multicolumn{3}{|c|}{$\Delta P_{3}(y)=5.43^{*}$} \\
\hline
\end{tabular}

Notes: Cases 1-9 correspond to the quasi-experimental changes in the menu, i.e., where only a single item was newly introduced to the menu. The compromise effect measures displayed in this table correspond to the measures introduced in Section 3.2 , with e.g. $\Delta P_{1}(y)=P(y ; T)-P(y ; S), \Delta P_{2}(y)=P(y, v ; T)-P(y, v ; S)$ and $\Delta P_{3}(y)=P(y, S-y ; T)-P(y, S-y ; S)$, with $S$ being the smaller and $T$ being the larger set of choices. All compromise effect measures are expressed in percentage points and were computed for the alternative that was exposed to the compromise effect (in bold). $P$-values in parentheses. ${ }^{*} \mathrm{p}<0.1,{ }^{* *}$ $\mathrm{p}<0.05, * * * \mathrm{p}<0.01$. 
Table 4: Compromise effects regressions

\begin{tabular}{|c|c|c|c|c|c|c|c|c|c|}
\hline & case 1 & case 2 & case 3 & case 4 & case 5 & case 6 & case 7 & case 8 & case 9 \\
\hline $\begin{array}{l}\text { marginal effect } \\
\text { (no control variables) }\end{array}$ & $\begin{array}{l}0.0220 \\
(0.197)\end{array}$ & $\begin{array}{l}0.0455 \\
(0.321)\end{array}$ & $\begin{array}{c}\mathbf{0 . 0 4 9 6} * \\
(0.077)\end{array}$ & $\begin{array}{r}-0.0170 \\
(0.666)\end{array}$ & $\begin{array}{c}\mathbf{0 . 0 4 7 1} * * * \\
(0.000)\end{array}$ & $\begin{array}{c}\mathbf{0 . 2 2 6 9} * * * \\
\quad(0.000)\end{array}$ & $\begin{array}{c}\mathbf{0 . 0 8 1 1} * * \\
\quad(0.019)\end{array}$ & $\begin{array}{c}\mathbf{0 . 0 4 3 5 *} \\
(0.073)\end{array}$ & $\begin{array}{l}0.0543 \\
(0.137)\end{array}$ \\
\hline Prob $>$ chi2 & 0.2121 & 0.7506 & 0.0052 & 0.8124 & 0.0000 & 0.0000 & 0.0413 & 0.000 & 0.2080 \\
\hline Log Likelihood & -1841.7292 & -590.96752 & -1329.9726 & -703.19099 & -9801.8057 & -478.44243 & -657.1973 & -1303.3907 & -655.76913 \\
\hline $\mathrm{N}$ obs & 5,990 & 1,815 & 3,936 & 2,100 & 27,363 & 1,434 & 1,902 & 4,368 & 2,270 \\
\hline $\mathrm{N}$ cases & 1,198 & 363 & 984 & 525 & 9,121 & 478 & 634 & 1,092 & 454 \\
\hline $\begin{array}{l}\text { marginal effect } \\
\text { (control variables) }\end{array}$ & $\begin{array}{l}0.0159 \\
(0.425)\end{array}$ & $\begin{array}{l}-0.033 \\
(0.696)\end{array}$ & $\begin{array}{l}0.0163 \\
(0.774)\end{array}$ & $\begin{array}{c}-0.0883 \\
(0.197)\end{array}$ & $\begin{array}{c}\mathbf{0 . 0 3 0 6} * * * \\
(0.037)\end{array}$ & $\begin{array}{c}\mathbf{0 . 2 7 0} * * * \\
(0.000)\end{array}$ & $\begin{array}{l}0.0482 \\
(0.427)\end{array}$ & $\begin{array}{c}\mathbf{0 . 1 1 1} * * * \\
(0.000)\end{array}$ & $\begin{array}{l}0.0965 \\
(0.435)\end{array}$ \\
\hline Prob > chi2 & 0.0002 & 0.0000 & 0.0000 & 0.0003 & 0.0000 & 0.0001 & 0.0003 & 0.0000 & 0.0001 \\
\hline Log Likelihood & -1812.9257 & -473.48776 & -1289.9225 & -677.65195 & -9603.446 & -468.94195 & -639.46458 & -1232.3855 & -618.93288 \\
\hline $\mathrm{N}$ obs & 5,990 & 1,815 & 3,936 & 2,100 & 27,363 & 1,434 & 1,902 & 4,368 & 2,270 \\
\hline $\mathrm{N}$ cases & 1,198 & 363 & 984 & 525 & 9,121 & 478 & 634 & 1,092 & 454 \\
\hline
\end{tabular}

Notes: The case-specific marginal effect refers to the alternative that was exposed to the compromise effect (see alternatives in bold in Table 3). Control variables used to obtain the bottom estimates were an indicator variable for outside table, business climate, indicator for public holiday, weekend and evening indicators and the number of main dishes on the bill. Standard errors were computed using the delta method. P-values in parentheses. * $\mathrm{p}<0.1, * * \mathrm{p}<0.05, * * * \mathrm{p}<0.01$. 
Table 5: Marginal effects category 1 (traditional dishes)

\begin{tabular}{|c|c|c|c|c|c|c|}
\hline \multirow[b]{3}{*}{ dish 1} & \multicolumn{6}{|c|}{ Marginal effects of the position coefficient (percent) } \\
\hline & \multicolumn{2}{|c|}{$\begin{array}{c}\text { first } \\
\text { position }\end{array}$} & \multicolumn{2}{|c|}{$\begin{array}{c}\text { last } \\
\text { position }\end{array}$} & \multicolumn{2}{|c|}{$\begin{array}{l}\text { median } \\
\text { position }\end{array}$} \\
\hline & $-0.100^{* * *}$ & $-0.131^{* * *}$ & $0.963^{* * *}$ & $1.263^{* * *}$ & 0.0350 & 0.0400 \\
\hline $\operatorname{dish} 2$ & $-0.099^{* * *}$ & $-0.130^{* * *}$ & $0.964^{* * *}$ & $1.276^{* * *}$ & 0.0350 & 0.0400 \\
\hline dish3 & $-0.101^{* * *}$ & $-0.133^{* * *}$ & $0.536^{* * *}$ & $0.615^{* * *}$ & 0.0350 & 0.0410 \\
\hline $\operatorname{dish} 4$ & $-0.110^{* * *}$ & $-0.152^{* * *}$ & $0.986^{* * *}$ & $1.382^{* * *}$ & 0.0350 & 0.0410 \\
\hline $\operatorname{dish} 5$ & $-0.105^{* * *}$ & $-0.137^{* * *}$ & $1.025^{* * *}$ & $1.358^{* * *}$ & 0.0360 & 0.0410 \\
\hline $\operatorname{dish} 6$ & $-0.107^{* * *}$ & $-0.144^{* * *}$ & $0.926^{* * *}$ & $1.207^{* * *}$ & 0.0340 & 0.0390 \\
\hline $\operatorname{dish} 7$ & $-0.094^{* * *}$ & $-0.122^{* * *}$ & $0.850^{* * *}$ & $1.084^{* * *}$ & 0.0320 & 0.0360 \\
\hline dish 8 & $-0.102^{* * *}$ & $-0.134^{* * *}$ & $0.960^{* * *}$ & $1.256^{* * *}$ & 0.0350 & 0.0400 \\
\hline dish9 & $-0.099^{* * *}$ & $-0.129^{* * *}$ & $0.919^{* * *}$ & $1.204^{* * *}$ & 0.0340 & 0.0390 \\
\hline $\operatorname{dish} 10$ & $-0.095^{* * *}$ & $-0.124^{* * *}$ & $0.608^{* * *}$ & $0.725^{* * *}$ & 0.0330 & 0.0380 \\
\hline dish 11 & $-0.102^{* * *}$ & $-0.133^{* * *}$ & $0.540^{* * *}$ & $0.616^{* * *}$ & 0.0360 & 0.0410 \\
\hline $\operatorname{dish} 12$ & $-0.105^{* * *}$ & $-0.137^{* * *}$ & $1.070^{* * *}$ & $1.429^{* * *}$ & 0.0360 & 0.0400 \\
\hline $\operatorname{dish} 13$ & $-0.103^{* * *}$ & $-0.133^{* * *}$ & $1.031^{* * *}$ & $1.329^{* * *}$ & 0.0350 & 0.0390 \\
\hline dish 14 & $-0.098^{* * *}$ & $-0.129^{* * *}$ & $1.029^{* * *}$ & $1.400^{* * *}$ & 0.0340 & 0.0390 \\
\hline$N$ & 165571 & 165571 & 165571 & 165571 & 165571 & 165571 \\
\hline constant & Yes & Yes & Yes & Yes & Yes & Yes \\
\hline price & Yes & Yes & Yes & Yes & Yes & Yes \\
\hline first position & Yes & Yes & No & No & No & No \\
\hline last position & No & No & Yes & Yes & No & No \\
\hline median position & No & No & No & No & Yes & Yes \\
\hline business climate & No & Yes & No & Yes & No & Yes \\
\hline weekend & No & Yes & No & Yes & No & Yes \\
\hline evening & No & Yes & No & Yes & No & Yes \\
\hline number of main dishes on bill & No & Yes & No & Yes & No & Yes \\
\hline Log lik. & -44697.9 & -44139.6 & -44442.6 & -43839.7 & -44699.8 & -44142.7 \\
\hline $\mathrm{AIC}$ & 89425.8 & 88413.2 & 88915.2 & 87813.3 & 89429.5 & 88419.4 \\
\hline $\mathrm{BIC}$ & 89576.0 & 89084.4 & 89065.5 & 88484.5 & 89579.8 & 89090.5 \\
\hline
\end{tabular}

Notes: All marginal effects are percentages computed from a conditional logit model. If the position is indicated by a dummy variable (first position, last position, median position) $\mathrm{dp} / \mathrm{dx}$ is computed for discrete change of indicator variable from 0 to 1 . The percentage changes in response to a one Euro increase in the respective price (own-price effects) in a model that controls for extreme positions and a constant are $-0.224^{* * *}(\operatorname{dish} 1),-0.221^{* * *}(\operatorname{dish} 2),-0.228^{* * *}(\operatorname{dish} 3),-0.224 * * *(\operatorname{dish} 4),-0.231^{* * * *}$ (dish 5), -0.217*** (dish 6), $-0.208^{* * *}$ (dish 7), -0.223*** (dish 8), -0.221*** (dish 9), -0.213*** (dish 10), -0.232*** (dish 11), $-0.236^{* * *}$ (dish 12), $-0.230^{* * *}$ (dish 13), $-0.222^{* * *}$ (dish 14). Significance levels refer to one-sided t-tests. $P$-values in parentheses. ${ }^{*} \mathrm{p}<0.1,{ }^{* *} \mathrm{p}<0.05,{ }^{* * *} \mathrm{p}<0.01$. 
Table 6: Marginal effects category 2 (fish)

\begin{tabular}{|c|c|c|c|c|c|c|}
\hline \multirow[b]{3}{*}{ dish 1} & \multicolumn{6}{|c|}{ Marginal effects of the position coefficient (percent) } \\
\hline & \multicolumn{2}{|c|}{$\begin{array}{c}\text { first } \\
\text { position }\end{array}$} & \multicolumn{2}{|c|}{$\begin{array}{c}\text { last } \\
\text { position }\end{array}$} & \multicolumn{2}{|c|}{$\begin{array}{l}\text { median } \\
\text { position }\end{array}$} \\
\hline & -0.067 & -0.062 & $-0.499^{* * *}$ & -0.607 & $0.315^{* * *}$ & 0.354 \\
\hline dish2 & $-0.064^{*}$ & -0.057 & $-0.328^{* * *}$ & $-0.362^{* * *}$ & $0.243^{* * *}$ & $0.258^{* * *}$ \\
\hline dish3 & $-0.067^{*}$ & -0.060 & $-0.451^{* * *}$ & $-0.514^{* * *}$ & $0.295^{* * *}$ & $0.316^{* * *}$ \\
\hline $\operatorname{dish} 4$ & $-0.067^{*}$ & -0.061 & $-0.505^{* * *}$ & -0.583 & $0.316^{* * *}$ & 0.343 \\
\hline $\operatorname{dish} 5$ & $-0.067^{*}$ & -0.060 & $-0.420^{* * *}$ & $-0.475^{* * *}$ & $0.279^{* * *}$ & $0.298^{* * *}$ \\
\hline $\operatorname{dish} 6$ & -0.068 & -0.061 & $-0.510^{* * *}$ & $-0.589^{* * *}$ & $0.321^{* * *}$ & $0.346^{* * *}$ \\
\hline $\operatorname{dish} 7$ & $-0.067^{*}$ & -0.061 & $-0.404^{* * *}$ & $-0.458^{* * *}$ & $0.271^{* * *}$ & $0.294^{* * *}$ \\
\hline $\operatorname{dish} 8$ & -0.068 & -0.060 & $-0.343^{* * *}$ & -0.372 & $0.246^{* * *}$ & 0.257 \\
\hline dish9 & $-0.068^{*}$ & -0.061 & $-0.341^{* * *}$ & $-0.375^{* * *}$ & $0.296^{* * *}$ & $0.317^{* * *}$ \\
\hline $\operatorname{dish} 10$ & -0.066 & -0.059 & $-0.329^{* * *}$ & $-0.363^{* * *}$ & $0.298^{* * *}$ & $0.323^{*}$ \\
\hline dish 11 & $-0.064^{*}$ & -0.056 & $-0.466^{* * *}$ & $-0.520^{* *}$ & $0.294^{* * *}$ & $0.309^{* *}$ \\
\hline dish12 & $-0.066^{*}$ & -0.060 & $-0.336^{* * *}$ & $-0.371^{* * *}$ & $0.311^{* * *}$ & $0.339 * * *$ \\
\hline $\operatorname{dish} 13$ & -0.071 & -0.061 & $-0.334^{* * *}$ & -0.354 & $0.307^{* * *}$ & 0.311 \\
\hline dish14 & $-0.067^{*}$ & -0.060 & $-0.500^{* * *}$ & -0.578 & $0.314^{* * *}$ & 0.339 \\
\hline $\operatorname{dish} 15$ & -0.073 & -0.065 & $-0.341^{* * *}$ & $-0.375^{* * *}$ & $0.321^{* * *}$ & $0.347^{* * *}$ \\
\hline $\operatorname{dish} 16$ & $-0.066^{*}$ & -0.059 & $-0.409^{* * *}$ & $-0.463^{* * *}$ & $0.293^{* * *}$ & $0.315^{* * *}$ \\
\hline $\operatorname{dish} 17$ & $-0.064^{*}$ & -0.057 & $-0.325^{* * *}$ & -0.355 & $0.231^{* * *}$ & 0.242 \\
\hline $\operatorname{dish} 18$ & $-0.066^{*}$ & -0.059 & $-0.495^{* * *}$ & $-0.560^{* * *}$ & $0.311^{* * *}$ & $0.329^{* * *}$ \\
\hline dish 19 & $-0.064^{*}$ & -0.058 & $-0.429^{* * *}$ & $-0.481^{* * *}$ & $0.279^{* * *}$ & $0.298^{* * *}$ \\
\hline dish20 & $-0.066^{*}$ & -0.059 & $-0.336^{* * *}$ & $-0.368^{* * *}$ & $0.240^{* * *}$ & $0.253^{* * *}$ \\
\hline $\operatorname{dish} 21$ & $-0.067^{*}$ & -0.058 & $-0.497^{* * *}$ & -0.550 & $0.314^{* * *}$ & 0.327 \\
\hline $\operatorname{dish} 22$ & $-0.067^{*}$ & -0.060 & $-0.499^{* * *}$ & $-0.584^{* * *}$ & $0.313^{* * *}$ & $0.341^{* * *}$ \\
\hline$N$ & 61560 & 61560 & 61560 & 61560 & 61560 & 61560 \\
\hline constant & Yes & Yes & Yes & Yes & Yes & Yes \\
\hline price & Yes & Yes & Yes & Yes & Yes & Yes \\
\hline first position & Yes & Yes & No & No & No & No \\
\hline last position & No & No & Yes & Yes & No & No \\
\hline median position & No & No & No & No & Yes & Yes \\
\hline business climate & No & Yes & No & Yes & No & Yes \\
\hline weekend & No & Yes & No & Yes & No & Yes \\
\hline evening & No & Yes & No & Yes & No & Yes \\
\hline number of main dishes on bill & No & Yes & No & Yes & No & Yes \\
\hline Log lik. & -19255.0 & -18891.7 & -19209.8 & -18846.0 & -19222.6 & -18862.3 \\
\hline $\mathrm{AIC}$ & 38556.0 & 37997.5 & 38465.6 & 37905.9 & 38491.2 & 37938.6 \\
\hline $\mathrm{BIC}$ & 38763.6 & 38963.5 & 38673.2 & 38871.9 & 38698.9 & 38904.5 \\
\hline
\end{tabular}

Notes: All marginal effects are percentages computed from a conditional logit model. If the position is indicated by a dummy variable (first position, last position, median position) $\mathrm{dp} / \mathrm{dx}$ is computed for discrete change of indicator variable from 0 to 1 . The percentage changes in response to a one Euro increase in the respective price (own-price effects) in a model that controls for extreme positions and a constant are $-0.115^{* * *}$ (dish 1$),-0.11^{* * *}($ dish 2$),-0.116^{* * *}($ dish 3$),-0.116^{* * *}($ dish 4$),-0.115^{* * *}($ dish $5),-0.116^{* * *}(\operatorname{dish} 6),-0.115^{* * *}(\operatorname{dish} 7),-0.118^{* * *}(\operatorname{dish} 8),-0.117^{* * *}(\operatorname{dish} 9),-0.11^{* * *}(\operatorname{dish} 10),-0.11^{* * *}(\operatorname{dish} 11),-0.114^{* * *}$ (dish 12), $-0.113^{* * *}$ (dish 13), $-0.115^{* * *}$ (dish 14),$-0.117^{* * *}$ (dish 15) , $-0.113^{* * *}$ (dish 16),$-0.109^{* * *}$ (dish 17),$-0.114^{* * *}$ $($ dish 18$),-0.111^{* * *}(\operatorname{dish} 19),-0.114^{* * *}(\operatorname{dish} 20),-0.114^{* * *}(\operatorname{dish} 21),-0.115^{* * *}(\operatorname{dish} 22) . P$-values in parentheses. ${ }^{*} \mathrm{p}<$ $0.1, * * \mathrm{p}<0.05, * * * \mathrm{p}<0.01$. 
Table 7: Marginal effects category 3 (venison)

\begin{tabular}{|c|c|c|c|c|c|c|}
\hline \multirow[b]{3}{*}{ dish1 } & \multicolumn{6}{|c|}{ Marginal effects of the position coefficient (percent) } \\
\hline & \multicolumn{2}{|c|}{$\begin{array}{c}\text { first } \\
\text { position }\end{array}$} & \multicolumn{2}{|c|}{$\begin{array}{c}\text { last } \\
\text { position }\end{array}$} & \multicolumn{2}{|c|}{$\begin{array}{l}\text { median } \\
\text { position }\end{array}$} \\
\hline & $0.108^{* *}$ & 0.066 & $-3.139^{* * *}$ & $-3.547^{* * *}$ & -0.029 & 0.013 \\
\hline $\operatorname{dish} 2$ & $0.093^{* *}$ & 0.054 & $-0.858^{* * *}$ & $-0.922^{* * *}$ & -0.026 & 0.010 \\
\hline $\operatorname{dish} 3$ & $0.102^{* *}$ & 0.061 & $-1.691^{* * *}$ & $-1.919^{* * *}$ & -0.028 & 0.012 \\
\hline $\operatorname{dish} 4$ & $0.107^{* *}$ & 0.070 & $-2.823^{* * *}$ & -5.569 & -0.029 & 0.013 \\
\hline $\operatorname{dish} 5$ & $0.114^{* *}$ & 0.069 & $-0.815^{* * *}$ & $-0.864^{* * *}$ & -0.031 & 0.013 \\
\hline $\operatorname{dish} 6$ & $0.099^{* * *}$ & 0.067 & $-1.006^{* * *}$ & -1.155 & -0.029 & 0.014 \\
\hline $\operatorname{dish} 7$ & $0.090^{* * *}$ & 0.054 & $-0.807^{* * *}$ & $-0.863^{* * *}$ & -0.026 & 0.011 \\
\hline $\operatorname{dish} 8$ & $0.110^{* *}$ & 0.065 & $-3.132^{* * *}$ & $-3.813^{* * *}$ & -0.030 & 0.013 \\
\hline dish9 & $0.096^{* * *}$ & 0.057 & $-0.876^{* * *}$ & $-0.943^{* * *}$ & -0.027 & 0.011 \\
\hline$N$ & 56402 & 56402 & 56402 & 56402 & 56402 & 56402 \\
\hline constant & Yes & Yes & Yes & Yes & Yes & Yes \\
\hline price & Yes & Yes & Yes & Yes & Yes & Yes \\
\hline first position & Yes & Yes & No & No & No & No \\
\hline last position & No & No & Yes & Yes & No & No \\
\hline median position & No & No & No & No & Yes & Yes \\
\hline business climate & No & Yes & No & Yes & No & Yes \\
\hline weekend & No & Yes & No & Yes & No & Yes \\
\hline evening & No & Yes & No & Yes & No & Yes \\
\hline number of main dishes on bill & No & Yes & No & Yes & No & Yes \\
\hline Log lik. & -18827.0 & -18605.0 & -18053.9 & -17690.6 & -18829.9 & -18605.7 \\
\hline $\mathrm{AIC}$ & 37674.0 & 37294.0 & 36127.8 & 35465.2 & 37679.7 & 37295.4 \\
\hline $\mathrm{BIC}$ & 37763.4 & 37669.5 & 36217.2 & 35840.7 & 37769.1 & 37670.9 \\
\hline
\end{tabular}

Notes: All marginal effects are percentages computed from a conditional logit model. If the position is indicated by a dummy variable (first position, last position, median position) $\mathrm{dp} / \mathrm{dx}$ is computed for discrete change of indicator variable from 0 to 1 . The percentage changes in response to a one Euro increase in the respective price (own-price effects) in a model that controls for extreme positions and a constant are $-0.424^{* * *}(\operatorname{dish} 1),-0.364^{* * *}(\operatorname{dish} 2),-0.409^{* * *}(\operatorname{dish} 3),-0.415^{* * *}(\operatorname{dish} 4),-0.44^{* * *}$ $($ dish 5$),-0.424^{* * *}(\operatorname{dish} 6),-0.387^{* * *}(\operatorname{dish} 7),-0.426^{* * *}(\operatorname{dish} 8),-0.387^{* * *}(\operatorname{dish} 9) . P$-values in parentheses. ${ }^{*} \mathrm{p}<0.1,{ }^{* *} \mathrm{p}$ $<0.05, * * * \mathrm{p}<0.01$. 
Table 8: Marginal effects category 4 (steaks)

\begin{tabular}{|c|c|c|c|c|c|c|}
\hline \multirow[b]{3}{*}{$\operatorname{dish} 1$} & \multicolumn{6}{|c|}{ Marginal effects of the position coefficient (percent) } \\
\hline & \multicolumn{2}{|c|}{$\begin{array}{c}\text { first } \\
\text { position }\end{array}$} & \multicolumn{2}{|c|}{$\begin{array}{c}\text { last } \\
\text { position }\end{array}$} & \multicolumn{2}{|c|}{$\begin{array}{l}\text { median } \\
\text { position }\end{array}$} \\
\hline & $-0.835^{* * *}$ & $-0.752^{* * *}$ & -0.025 & -0.00800 & $0.093^{* * *}$ & $0.093^{* * *}$ \\
\hline dish2 & $-0.829^{* * *}$ & $-0.743^{* * *}$ & -0.024 & -0.00700 & $0.090^{* * *}$ & $0.088^{* * *}$ \\
\hline $\operatorname{dish} 3$ & $-0.850^{* * *}$ & $-0.772^{* * *}$ & -0.029 & -0.00800 & $0.114^{* * *}$ & $0.112^{* * *}$ \\
\hline $\operatorname{dish} 4$ & $-0.833^{* * *}$ & $-0.750^{* * *}$ & -0.025 & -0.00700 & $0.097^{* * *}$ & $0.095^{* * *}$ \\
\hline dish 5 & $-0.817^{* * *}$ & $-0.727^{* * *}$ & -0.022 & -0.00700 & $0.085^{* * *}$ & $0.083^{* * *}$ \\
\hline $\operatorname{dish} 6$ & $-2.454^{* * *}$ & $-1.870^{* * *}$ & -0.025 & -0.00700 & $0.098^{* * *}$ & $0.098^{* * *}$ \\
\hline$N$ & 86387 & 86387 & 86387 & 86387 & 86387 & 86387 \\
\hline constant & Yes & Yes & Yes & Yes & Yes & Yes \\
\hline price & Yes & Yes & Yes & Yes & Yes & Yes \\
\hline first position & Yes & Yes & No & No & No & No \\
\hline last position & No & No & Yes & Yes & No & No \\
\hline median position & No & No & No & No & Yes & Yes \\
\hline business climate & No & No & No & Yes & No & Yes \\
\hline weekend & No & Yes & No & Yes & No & Yes \\
\hline evening & No & Yes & No & Yes & No & Yes \\
\hline number of main dishes on bill & No & Yes & No & Yes & No & Yes \\
\hline Log lik. & -27000.3 & -26655.3 & -26999.6 & -26654.4 & -26991.5 & -26647.7 \\
\hline $\mathrm{AIC}$ & 54012.5 & 53362.7 & 54013.2 & 53362.8 & 53997.1 & 53349.3 \\
\hline $\mathrm{BIC}$ & 54068.7 & 53606.2 & 54078.8 & 53615.7 & 54062.7 & 53602.2 \\
\hline
\end{tabular}

Notes: All marginal effects are percentages computed from a conditional logit model. Estimates displayed in columns 1 and 2 have to be interpreted with caution because the likelihood is not globally concave (too little variation in the data). If the position is indicated by a dummy variable (first position, last position, median position) $\mathrm{dp} / \mathrm{dx}$ is computed for discrete change of indicator variable from 0 to 1 . The percentage changes in response to a one Euro increase in the respective price (own-price effects) in a model that controls for extreme positions and a constant are $-0.329^{* * *}$ (dish 1$),-0.315^{* * *}$ (dish 2 ), $-0.367^{* * *}$ (dish 3), $-0.324^{* * *}$ (dish 4), $-0.29^{* * *}(\operatorname{dish} 5),-0.323^{* * *}(\operatorname{dish} 6)$. P-values in parentheses. ${ }^{*} \mathrm{p}<0.1,{ }^{* *} \mathrm{p}<0.05,{ }^{* * *} \mathrm{p}<0.01$. 
Table 9: Marginal effects category 5 (poultry)

\begin{tabular}{|c|c|c|c|c|c|c|}
\hline \multirow[b]{3}{*}{ dish1 } & \multicolumn{6}{|c|}{ Marginal effects of the position coefficient (percent) } \\
\hline & \multicolumn{2}{|c|}{$\begin{array}{c}\text { first } \\
\text { position }\end{array}$} & \multicolumn{2}{|c|}{$\begin{array}{c}\text { last } \\
\text { position }\end{array}$} & \multicolumn{2}{|c|}{$\begin{array}{l}\text { median } \\
\text { position }\end{array}$} \\
\hline & 0.010 & 0.109 & $-0.601^{* * *}$ & $-0.619^{* * *}$ & $0.139^{* * *}$ & 0.0880 \\
\hline dish2 & 0.010 & 0.110 & $-0.814^{* * *}$ & $-0.837^{* * *}$ & $0.154^{* * *}$ & 0.0940 \\
\hline dish3 & 0.009 & 0.103 & $-0.495^{* * *}$ & $-0.504^{* * *}$ & $0.129^{* * *}$ & 0.0820 \\
\hline $\operatorname{dish} 4$ & 0.010 & 0.100 & $-0.489^{* * *}$ & $-0.501^{* * *}$ & $0.151^{* * *}$ & 0.0930 \\
\hline $\operatorname{dish} 5$ & 0.011 & 0.109 & $-0.617^{* * *}$ & $-0.631^{* * *}$ & $0.166^{* * *}$ & 0.101 \\
\hline $\operatorname{dish} 6$ & 0.011 & 0.117 & $-0.832^{* * *}$ & $-0.858^{* * *}$ & $0.159^{* * *}$ & 0.0980 \\
\hline $\operatorname{dish} 7$ & 0.010 & 0.096 & $-0.544^{* * *}$ & $-0.553^{* * *}$ & $0.148^{* * *}$ & 0.0890 \\
\hline $\operatorname{dish} 8$ & 0.008 & 0.077 & $-0.423^{* * *}$ & $-0.430^{* * *}$ & $0.116^{* * *}$ & 0.0690 \\
\hline$N$ & 24928 & 24928 & 24928 & 24928 & 24928 & 24928 \\
\hline constant & Yes & Yes & Yes & Yes & Yes & Yes \\
\hline price & Yes & Yes & Yes & Yes & Yes & Yes \\
\hline first position & Yes & Yes & No & No & No & No \\
\hline last position & No & No & Yes & Yes & No & No \\
\hline median position & No & No & No & No & Yes & Yes \\
\hline business climate & No & Yes & No & Yes & No & Yes \\
\hline weekend & No & Yes & No & Yes & No & Yes \\
\hline evening & No & Yes & No & Yes & No & Yes \\
\hline number of main dishes on bill & No & Yes & No & Yes & No & Yes \\
\hline Log lik. & -8177.0 & -8066.3 & -8096.4 & -7990.9 & -8173.5 & -8065.3 \\
\hline $\mathrm{AIC}$ & 16371.9 & 16206.6 & 16210.8 & 16055.8 & 16365.0 & 16204.5 \\
\hline $\mathrm{BIC}$ & 16445.1 & 16507.2 & 16283.9 & 16356.4 & 16438.2 & 16505.1 \\
\hline
\end{tabular}

Notes: All marginal effects are percentages computed from a conditional logit model. If the position is indicated by a dummy variable (first position, last position, median position) $\mathrm{dp} / \mathrm{dx}$ is computed for discrete change of indicator variable from 0 to 1 . The percentage changes in response to a one Euro increase in the respective price (own-price effects) in a model that controls for extreme positions and a constant are $-0.111^{*}(\operatorname{dish} 1),-0.113^{*}(\operatorname{dish} 2),-0.106^{*}(\operatorname{dish} 3),-0.109(\operatorname{dish} 4),-0.12(\operatorname{dish} 5),-0.118$ (dish 6), -0.111 (dish 7), $-0.087^{*}($ dish 8$)$. P-values in parentheses. ${ }^{*} \mathrm{p}<0.1,{ }^{* *} \mathrm{p}<0.05,{ }^{* * *} \mathrm{p}<0.01$. 
Table 10: Marginal effects category 6 (vegetarian dishes)

\begin{tabular}{|c|c|c|c|c|c|c|}
\hline \multirow[b]{3}{*}{ dish1 } & \multicolumn{6}{|c|}{ Marginal effects of the position coefficient (percent) } \\
\hline & \multicolumn{2}{|c|}{$\begin{array}{c}\text { first } \\
\text { position }\end{array}$} & \multicolumn{2}{|c|}{$\begin{array}{c}\text { last } \\
\text { position }\end{array}$} & \multicolumn{2}{|c|}{$\begin{array}{l}\text { median } \\
\text { position }\end{array}$} \\
\hline & $-0.229^{* * *}$ & -0.138 & 0.015 & 0.013 & $0.088^{* *}$ & 0.106 \\
\hline $\operatorname{dish} 2$ & $-0.224^{* * *}$ & -0.139 & 0.014 & 0.013 & $0.086^{* *}$ & 0.106 \\
\hline dish3 & $-0.222^{* * *}$ & $-0.132^{*}$ & 0.014 & 0.013 & $0.086^{* *}$ & $0.101^{* *}$ \\
\hline $\operatorname{dish} 4$ & $-0.223^{* * *}$ & -0.131 & 0.014 & 0.012 & $0.085^{* *}$ & 0.100 \\
\hline $\operatorname{dish} 5$ & $-0.222^{* * *}$ & $-0.132^{*}$ & 0.014 & 0.013 & $0.090^{* *}$ & $0.107^{* *}$ \\
\hline $\operatorname{dish} 6$ & $-0.219^{* * *}$ & -0.139 & 0.014 & 0.013 & $0.091^{* *}$ & 0.119 \\
\hline $\operatorname{dish} 7$ & $-0.229^{* * *}$ & -0.138 & 0.015 & 0.013 & $0.091^{* *}$ & $0.109^{* *}$ \\
\hline dish8 & $-0.235^{* * *}$ & $-0.135^{*}$ & 0.014 & 0.012 & $0.091^{* *}$ & $0.108^{* *}$ \\
\hline dish9 & $-0.225^{* * *}$ & $-0.134^{*}$ & 0.014 & 0.013 & $0.094^{*}$ & $0.114^{* *}$ \\
\hline $\operatorname{dish} 10$ & $-0.224^{* * *}$ & $-0.132^{*}$ & 0.014 & 0.013 & $0.092^{* *}$ & $0.109^{* *}$ \\
\hline dish11 & $-0.222 * * *$ & -0.122 & 0.014 & 0.011 & $0.092^{*}$ & 0.101 \\
\hline $\operatorname{dish} 12$ & $-0.218^{* * *}$ & $-0.131^{*}$ & 0.014 & 0.013 & $0.084^{* *}$ & $0.100^{* *}$ \\
\hline $\operatorname{dish} 13$ & $-0.217^{* * *}$ & $-0.123^{*}$ & 0.014 & 0.012 & $0.083^{* *}$ & $0.094^{* *}$ \\
\hline $\operatorname{dish} 14$ & $-0.255^{* * *}$ & $-0.144^{*}$ & 0.014 & 0.013 & $0.090^{* *}$ & $0.108^{* *}$ \\
\hline $\operatorname{dish} 15$ & $-0.225^{* * *}$ & $-0.135^{*}$ & 0.014 & 0.013 & $0.094^{*}$ & $0.115^{*}$ \\
\hline $\operatorname{dish} 16$ & $-0.232^{* * *}$ & $-0.126^{*}$ & 0.012 & 0.011 & $0.079^{* *}$ & $0.094^{* *}$ \\
\hline$N$ & 39134 & 39134 & 39134 & 39134 & 39134 & 39134 \\
\hline constant & Yes & Yes & Yes & Yes & Yes & Yes \\
\hline price & Yes & Yes & Yes & Yes & Yes & Yes \\
\hline first position & Yes & Yes & No & No & No & No \\
\hline last position & No & No & Yes & Yes & No & No \\
\hline median position & No & No & No & No & Yes & Yes \\
\hline business climate & No & Yes & No & Yes & No & Yes \\
\hline weekend & No & Yes & No & Yes & No & Yes \\
\hline evening & No & Yes & No & Yes & No & Yes \\
\hline number of main dishes on bill & No & Yes & No & Yes & No & Yes \\
\hline Log lik. & -12028.2 & -11703.1 & -12037.7 & -11704.8 & -12035.5 & -11702.3 \\
\hline AIC & 24090.4 & 23560.2 & 24109.5 & 23563.6 & 24105.1 & 23558.7 \\
\hline $\mathrm{BIC}$ & 24236.2 & 24220.4 & 24255.2 & 24223.9 & 24250.9 & 24218.9 \\
\hline
\end{tabular}

Notes: All marginal effects are percentages computed from a conditional logit model. If the position is indicated by a dummy variable (first position, last position, median position) $\mathrm{dp} / \mathrm{dx}$ is computed for discrete change of indicator variable from 0 to 1 . The percentage changes in response to a one Euro increase in the respective price (own-price effects) in a model that controls for extreme positions and a constant are $0.147^{*}(\operatorname{dish} 1), 0.143^{*}(\operatorname{dish} 2), 0.142^{*}(\operatorname{dish} 3), 0.142^{*}(\operatorname{dish} 4), 0.141^{*}(\operatorname{dish} 5), 0.139^{*}$ (dish 6), 0.148** (dish 7), 0.140* (dish 8), 0.144* (dish 9), 0.143* (dish 10), 0.141* (dish 11), 0.138* (dish 12), 0.137* (dish 13), $0.142^{* *}\left(\right.$ dish 14) $0.144^{*}($ dish 15$), 0.122^{*}($ dish 16$)$. $P$-values in parentheses. $* \mathrm{p}<0.1, * * \mathrm{p}<0.05, * * * \mathrm{p}<0.01$. 
Table 11: Marginal effects, full choice set (part 1)

\begin{tabular}{|c|c|c|c|c|c|c|}
\hline \multirow[b]{3}{*}{ dish 1} & \multicolumn{6}{|c|}{ Marginal effects of the position coefficient (percent) } \\
\hline & \multicolumn{2}{|c|}{$\begin{array}{c}\text { first } \\
\text { position }\end{array}$} & \multicolumn{2}{|c|}{$\begin{array}{c}\text { last } \\
\text { position }\end{array}$} & \multicolumn{2}{|c|}{$\begin{array}{l}\text { median } \\
\text { position }\end{array}$} \\
\hline & 0.067 & 0.061 & $-0.181^{* * *}$ & $-0.179^{* * *}$ & 0.031 & 0.029 \\
\hline dish2 & 0.066 & 0.060 & $-0.180^{* * *}$ & $-0.179^{* * *}$ & 0.031 & 0.029 \\
\hline dish3 & 0.067 & 0.061 & $-0.219^{* *}$ & $-0.217^{* *}$ & 0.031 & 0.029 \\
\hline $\operatorname{dish} 4$ & 0.063 & 0.057 & $-0.183^{*}$ & -0.181 & 0.031 & 0.029 \\
\hline dish5 & 0.066 & 0.060 & $-0.182^{* * *}$ & $-0.180^{* * *}$ & 0.030 & 0.028 \\
\hline dish6 & 0.062 & 0.057 & $-0.180^{* * *}$ & $-0.179^{* * *}$ & 0.030 & 0.028 \\
\hline $\operatorname{dish} 7$ & 0.066 & 0.060 & $-0.179^{* * *}$ & $-0.177^{* * *}$ & 0.030 & 0.028 \\
\hline $\operatorname{dish} 8$ & 0.065 & 0.060 & $-0.182^{* * *}$ & $-0.180^{* * *}$ & 0.031 & 0.029 \\
\hline dish9 & 0.066 & 0.061 & $-0.183^{* * *}$ & $-0.181^{* * *}$ & 0.030 & 0.028 \\
\hline dish 10 & 0.066 & 0.060 & $-0.204^{* *}$ & $-0.202^{* *}$ & 0.030 & 0.028 \\
\hline dish 11 & 0.067 & 0.061 & -0.219 & -0.217 & 0.031 & 0.029 \\
\hline $\operatorname{dish} 12$ & 0.067 & 0.061 & $-0.181^{*}$ & $-0.180^{*}$ & 0.030 & 0.028 \\
\hline $\operatorname{dish} 13$ & 0.067 & 0.061 & $-0.182^{*}$ & $-0.181^{* *}$ & 0.030 & 0.028 \\
\hline $\operatorname{dish} 14$ & 0.067 & 0.061 & $-0.180^{*}$ & $-0.179^{*}$ & 0.031 & 0.029 \\
\hline dish 15 & 0.067 & 0.061 & -0.220 & -0.218 & 0.031 & 0.029 \\
\hline $\operatorname{dish} 16$ & 0.066 & 0.060 & $-0.181^{* * *}$ & $-0.179^{* * *}$ & 0.030 & 0.028 \\
\hline $\operatorname{dish} 17$ & 0.067 & 0.061 & -0.206 & -0.204 & 0.030 & 0.029 \\
\hline $\operatorname{dish} 18$ & 0.067 & 0.061 & -0.221 & -0.219 & 0.031 & 0.029 \\
\hline dish 19 & 0.067 & 0.061 & $-0.203^{* *}$ & $-0.201^{* *}$ & 0.030 & 0.028 \\
\hline dish 20 & 0.067 & 0.061 & -0.221 & -0.219 & 0.031 & 0.029 \\
\hline dish21 & 0.067 & 0.061 & $-0.197^{* *}$ & $-0.196^{* *}$ & 0.030 & 0.028 \\
\hline $\operatorname{dish} 22$ & 0.068 & 0.062 & -0.186 & -0.184 & 0.030 & 0.028 \\
\hline dish 23 & 0.067 & 0.061 & $-0.182^{* *}$ & $-0.180^{* *}$ & 0.031 & 0.029 \\
\hline dish 24 & 0.064 & 0.059 & $-0.181^{* * *}$ & $-0.180^{* * *}$ & 0.031 & 0.029 \\
\hline dish 25 & 0.066 & 0.060 & $-0.217^{* *}$ & $-0.215^{*}$ & 0.030 & 0.029 \\
\hline dish 26 & 0.067 & 0.061 & -0.181 & -0.180 & 0.031 & 0.029 \\
\hline $\operatorname{dish} 27$ & 0.062 & 0.057 & $-0.182^{* *}$ & $-0.180^{*}$ & 0.031 & 0.029 \\
\hline dish 28 & 0.067 & 0.061 & -0.220 & -0.219 & 0.031 & 0.029 \\
\hline dish29 & 0.063 & 0.058 & $-0.185^{* *}$ & $-0.183^{* *}$ & 0.031 & 0.029 \\
\hline dish 30 & 0.067 & 0.061 & $-0.198^{* *}$ & $-0.196^{* *}$ & 0.030 & 0.028 \\
\hline dish31 & 0.066 & 0.060 & $-0.178^{*}$ & $-0.177^{*}$ & 0.029 & 0.028 \\
\hline dish32 & 0.066 & 0.060 & $-0.215^{*}$ & $-0.213^{*}$ & 0.030 & 0.028 \\
\hline dish33 & 0.067 & 0.061 & $-0.206^{* *}$ & $-0.204^{* *}$ & 0.030 & 0.028 \\
\hline dish 34 & 0.067 & 0.061 & $-0.183^{*}$ & -0.181 & 0.030 & 0.028 \\
\hline dish 35 & 0.067 & 0.061 & $-0.220^{*}$ & $-0.218^{*}$ & 0.031 & 0.029 \\
\hline dish 36 & 0.067 & 0.061 & -0.218 & -0.216 & 0.031 & 0.029 \\
\hline dish 37 & 0.067 & 0.061 & $-0.219^{* *}$ & $-0.217^{*}$ & 0.031 & 0.029 \\
\hline dish38 & 0.066 & 0.060 & $-0.181^{* * *}$ & $-0.179^{* * *}$ & 0.030 & 0.028 \\
\hline dish39 & 0.067 & 0.061 & $-0.197^{* * *}$ & $-0.195^{* * *}$ & 0.030 & 0.028 \\
\hline $\operatorname{dish} 40$ & 0.067 & 0.061 & -0.220 & -0.218 & 0.031 & 0.029 \\
\hline dish41 & 0.067 & 0.061 & -0.181 & -0.180 & 0.030 & 0.028 \\
\hline $\operatorname{dish} 42$ & 0.062 & 0.057 & $-0.182^{*}$ & $-0.180^{*}$ & 0.030 & 0.028 \\
\hline $\operatorname{dish} 43$ & 0.062 & 0.057 & $-0.180^{* * *}$ & $-0.179^{* * *}$ & 0.030 & 0.028 \\
\hline dish 44 & 0.067 & 0.061 & -0.221 & -0.219 & 0.031 & 0.029 \\
\hline $\operatorname{dish} 45$ & 0.065 & 0.059 & $-0.182^{* * *}$ & $-0.180^{* * *}$ & 0.030 & 0.028 \\
\hline $\operatorname{dish} 46$ & 0.067 & 0.061 & $-0.184^{* * *}$ & $-0.182^{* * *}$ & 0.030 & 0.028 \\
\hline $\operatorname{dish} 47$ & 0.066 & 0.060 & $-0.179^{* * *}$ & $-0.177^{* * *}$ & 0.029 & 0.028 \\
\hline $\operatorname{dish} 48$ & 0.067 & 0.061 & $-0.220^{* *}$ & $-0.218^{* *}$ & 0.031 & 0.029 \\
\hline $\operatorname{dish} 49$ & 0.066 & 0.060 & $-0.188^{* * *}$ & $-0.186^{* * *}$ & 0.030 & 0.028 \\
\hline $\operatorname{dish} 50$ & 0.066 & 0.060 & $-0.180^{* * *}$ & $-0.179^{* * *}$ & 0.030 & 0.028 \\
\hline
\end{tabular}

Continued on next page ... 
Table 12: Marginal effects, full choice set (part 2)

\begin{tabular}{|c|c|c|c|c|c|c|}
\hline \multirow[b]{3}{*}{ dish51 } & \multicolumn{6}{|c|}{ Marginal effects of the position coefficient (percent) } \\
\hline & \multicolumn{2}{|c|}{$\begin{array}{c}\text { first } \\
\text { position }\end{array}$} & \multicolumn{2}{|c|}{$\begin{array}{c}\text { last } \\
\text { position }\end{array}$} & \multicolumn{2}{|c|}{$\begin{array}{c}\text { median } \\
\text { position }\end{array}$} \\
\hline & 0.062 & 0.057 & $-0.181^{* * *}$ & $-0.180^{* * *}$ & 0.030 & 0.028 \\
\hline $\operatorname{dish} 52$ & 0.067 & 0.061 & $-0.193^{* *}$ & $-0.192^{* *}$ & 0.030 & 0.028 \\
\hline $\operatorname{dish} 53$ & 0.067 & 0.061 & $-0.218^{* *}$ & $-0.217^{* *}$ & 0.031 & 0.029 \\
\hline $\operatorname{dish} 54$ & 0.066 & 0.060 & $-0.182^{* * *}$ & $-0.180^{* * *}$ & 0.030 & 0.028 \\
\hline $\operatorname{dish} 55$ & 0.062 & 0.057 & $-0.180^{* * *}$ & $-0.178^{* * *}$ & 0.030 & 0.028 \\
\hline $\operatorname{dish} 56$ & 0.064 & 0.059 & $-0.192^{* * *}$ & $-0.190^{* *}$ & 0.031 & 0.029 \\
\hline $\operatorname{dish} 57$ & 0.067 & 0.061 & $-0.215^{* *}$ & $-0.213^{* *}$ & 0.031 & 0.029 \\
\hline $\operatorname{dish} 58$ & 0.062 & 0.057 & $-0.179^{*}$ & $-0.178^{*}$ & 0.030 & 0.028 \\
\hline $\operatorname{dish} 59$ & 0.060 & 0.055 & $-0.176^{* * *}$ & $-0.174^{* * *}$ & 0.029 & 0.027 \\
\hline dish 60 & 0.067 & 0.061 & $-0.182^{*}$ & $-0.181^{*}$ & 0.030 & 0.028 \\
\hline $\operatorname{dish} 61$ & 0.067 & 0.061 & -0.184 & -0.183 & 0.030 & 0.028 \\
\hline $\operatorname{dish} 62$ & 0.067 & 0.061 & $-0.185^{* * *}$ & $-0.183^{* * *}$ & 0.030 & 0.028 \\
\hline $\operatorname{dish} 63$ & 0.067 & 0.061 & -0.181 & -0.180 & 0.030 & 0.028 \\
\hline dish64 & 0.067 & 0.061 & $-0.186^{* * *}$ & $-0.185^{* *}$ & 0.030 & 0.029 \\
\hline $\operatorname{dish} 65$ & 0.067 & 0.061 & -0.220 & -0.218 & 0.031 & 0.029 \\
\hline $\operatorname{dish} 66$ & 0.067 & 0.061 & -0.198 & -0.196 & 0.030 & 0.029 \\
\hline $\operatorname{dish} 67$ & 0.065 & 0.060 & $-0.183^{* * *}$ & $-0.181^{* * *}$ & 0.031 & 0.029 \\
\hline $\operatorname{dish} 68$ & 0.067 & 0.061 & $-0.220^{* *}$ & $-0.218^{* *}$ & 0.031 & 0.029 \\
\hline $\operatorname{dish} 69$ & 0.067 & 0.061 & $-0.207^{* *}$ & $-0.205^{* *}$ & 0.031 & 0.029 \\
\hline $\operatorname{dish} 70$ & 0.067 & 0.061 & $-0.218^{*}$ & $-0.216^{*}$ & 0.031 & 0.029 \\
\hline $\operatorname{dish} 71$ & 0.067 & 0.061 & $-0.181^{* *}$ & $-0.180^{*}$ & 0.030 & 0.028 \\
\hline $\operatorname{dish} 72$ & 0.066 & 0.060 & $-0.181^{*}$ & $-0.180^{*}$ & 0.030 & 0.028 \\
\hline $\operatorname{dish} 73$ & 0.064 & 0.059 & $-0.181^{* *}$ & $-0.180^{* *}$ & 0.030 & 0.028 \\
\hline $\operatorname{dish} 74$ & 0.067 & 0.061 & -0.221 & -0.219 & 0.031 & 0.029 \\
\hline $\operatorname{dish} 75$ & 0.062 & 0.057 & $-0.181^{* * *}$ & $-0.180^{* * *}$ & 0.030 & 0.028 \\
\hline$N$ & 82100 & 82100 & 82100 & 82100 & 82100 & 82100 \\
\hline constant & Yes & Yes & Yes & Yes & Yes & Yes \\
\hline price & Yes & Yes & Yes & Yes & Yes & Yes \\
\hline first position & Yes & Yes & No & No & No & No \\
\hline last position & No & No & Yes & Yes & No & No \\
\hline median position & No & No & No & No & Yes & Yes \\
\hline number of main dishes on bill & No & Yes & No & Yes & No & Yes \\
\hline Log lik. & -9973.4 & -9904.4 & -9969.9 & -9901.0 & -9973.5 & -9904.5 \\
\hline AIC & 20098.8 & 20108.8 & 20091.9 & 20101.9 & 20099.0 & 20108.9 \\
\hline $\mathrm{BIC}$ & 20806.8 & 21506.1 & 20799.9 & 21499.3 & 20807.0 & 21506.3 \\
\hline
\end{tabular}

Notes: All marginal effects are percentages computed from a conditional logit model. If the position is indicated by a dummy variable (first position, last position, median position) $\mathrm{dp} / \mathrm{dx}$ is computed for discrete change of indicator variable from 0 to 1 . The percentage changes in response to a one Euro increase in the respective price (own-price effects) in a model that controls for extreme positions and a constant are $-0.201^{* *}(\operatorname{dish} 1),-0.2^{* *}(\operatorname{dish} 2),-0.202^{* *}(\operatorname{dish} 3),-0.202(\operatorname{dish} 4),-0.202^{* *}(\operatorname{dish} 5)$, $-0.199^{* *}(\operatorname{dish} 6),-0.198^{* * *}(\operatorname{dish} 7),-0.2^{* *}(\operatorname{dish} 8),-0.201^{* *}(\operatorname{dish} 9),-0.199^{* *}(\operatorname{dish} 10),-0.202$ (dish 11), $-0.203^{*}($ dish 12), $-0.203^{*}$ (dish 13), -0.201* (dish 14), -0.203 (dish 15), -0.2** (dish 16), -0.202 (dish 17), -0.203 (dish 18), -0.202** (dish 19), $-0.202^{* *}($ dish 20$),-0.203$ (dish 21),-0.204 (dish 22), -0.203** (dish 23), $-0.2^{* *}$ (dish 24), $-0.2^{* *}$ (dish 25), $-0.204^{* *}$ (dish 26), $-0.201^{*}$ (dish 27), -0.203 (dish 28), $-0.203^{* *}$ (dish 29), -0.201** (dish 30), -0.199* (dish 31), -0.199* (dish 32), $-0.201 * *$ (dish 33), -0.201 (dish 34), $-0.202^{*}$ (dish 35), -0.201 (dish 36), -0.202** (dish 37), -0.2** (dish 38), -0.201** (dish 39), -0.202 (dish 40), -0.203 (dish 41),$-0.2^{*}$ (dish 42), $-0.2^{* *}(\operatorname{dish} 43),-0.203$ (dish 44), $-0.201^{* *}(\operatorname{dish} 45),-0.201^{* *}(\operatorname{dish} 46),-0.198^{* * *}(\operatorname{dish}$ 47), $-0.203^{* *}$ (dish 48), $-0.2^{* *}$ (dish 49), $-0.199^{* *}$ (dish 50), $-0.2^{* *}$ (dish 51), -0.201** (dish 52), $-0.201 * *$ (dish 53), $-0.2^{* *}$ (dish $54),-0.2^{* *}$ (dish 55), $-0.203^{* *}$ (dish 56), $-0.202^{* *}$ (dish 57), $-0.2^{* *}$ (dish 58), $-0.193^{* * *}$ (dish 59), $-0.202^{*}$ (dish 60), -0.203 (dish 61 ), $-0.202^{* *}$ (dish 62), -0.203 (dish 63), -0.202** (dish 64), -0.203 (dish 65), -0.203 (dish 66), -0.202** (dish 67), -0.203** (dish 68), $-0.203^{* *}(\operatorname{dish} 69),-0.201^{* *}(\operatorname{dish} 70),-0.202^{* *}(\operatorname{dish} 71),-0.2^{*}(\operatorname{dish} 72),-0.202^{* *}(\operatorname{dish} 73),-0.204(\operatorname{dish} 74),-0.199^{* * *}$ $($ dish 75$) . P$-values in parentheses. ${ }^{*} \mathrm{p}<0.1,{ }^{* *} \mathrm{p}<0.05,{ }^{* * *} \mathrm{p}<0.01$. 
Table 13: Conditional logit full choice set

\begin{tabular}{|c|c|c|c|c|}
\hline \multirow[b]{2}{*}{ price of item (per unit) } & \multicolumn{2}{|c|}{ extremes } & \multicolumn{2}{|c|}{ median position } \\
\hline & $\begin{array}{c}-0.204^{* *} \\
(0.01)\end{array}$ & $\begin{array}{c}-0.208^{* * *} \\
(0.01)\end{array}$ & $\begin{array}{c}-0.205^{* * *} \\
(0.01)\end{array}$ & $\begin{array}{c}-0.209^{* * * *} \\
(0.01)\end{array}$ \\
\hline first position within category & $\begin{array}{c}0.0612 \\
(0.53)\end{array}$ & $\begin{array}{c}0.0558 \\
(0.57)\end{array}$ & & \\
\hline last position within category & $\begin{array}{c}-0.200^{* * *} \\
(0.01)\end{array}$ & $\begin{array}{c}-0.198^{* * *} \\
(0.01)\end{array}$ & & \\
\hline median position within category & & & $\begin{array}{c}0.0306 \\
(0.61)\end{array}$ & $\begin{array}{c}0.0287 \\
(0.63)\end{array}$ \\
\hline constant & Yes & Yes & Yes & Yes \\
\hline number of main dishes on bill & No & Yes & No & Yes \\
\hline$N$ & 82100 & 82100 & 82100 & 82100 \\
\hline Log lik. & -9969.7 & -9900.8 & -9973.5 & -9904.5 \\
\hline AIC & 20093.5 & 20103.6 & 20099.0 & 20108.9 \\
\hline $\mathrm{BIC}$ & 20810.8 & 21510.3 & 20807.0 & 21506.3 \\
\hline
\end{tabular}

Notes: Estimates are based on a random draw from the full dataset. $P$-values in parentheses. $* \mathrm{p}<0.1, * * \mathrm{p}<0.05, * * * \mathrm{p}$ $<0.01$.

Table 14: Mixed logit full choice set

\begin{tabular}{|c|c|c|c|c|}
\hline \multirow[b]{2}{*}{ price of item (per unit) } & \multicolumn{2}{|c|}{ extremes } & \multicolumn{2}{|c|}{ median position } \\
\hline & $\begin{array}{l}-0.210^{* * *} \\
\quad(0.01)\end{array}$ & $\begin{array}{l}-0.216^{* * *} \\
\quad(0.01)\end{array}$ & $\begin{array}{l}-0.205^{* * *} \\
\quad(0.01)\end{array}$ & $\begin{array}{l}-0.210^{* * *} \\
\quad(0.01)\end{array}$ \\
\hline first position within category & $\begin{array}{c}0.0410 \\
(0.75)\end{array}$ & $\begin{array}{c}0.0494 \\
(0.64)\end{array}$ & & \\
\hline last position within category & $\begin{array}{l}-0.413^{* * *} \\
\quad(0.00)\end{array}$ & $\begin{array}{l}-0.447^{* * *} \\
\quad(0.00)\end{array}$ & & \\
\hline median position within category & & & $\begin{array}{c}0.0252 \\
(0.71)\end{array}$ & $\begin{array}{c}0.0268 \\
(0.66)\end{array}$ \\
\hline $\begin{array}{l}\text { SD } \\
\text { price of item (per unit) }\end{array}$ & $\begin{array}{c}0.0756 \\
(0.55)\end{array}$ & $\begin{array}{c}-0.0922 \\
(0.40)\end{array}$ & $\begin{array}{c}-0.0118 \\
(0.91)\end{array}$ & $\begin{array}{c}-0.0133 \\
(0.88)\end{array}$ \\
\hline first position within category & $\begin{array}{l}0.301 \\
(0.62)\end{array}$ & $\begin{array}{l}0.173 \\
(0.73)\end{array}$ & & \\
\hline last position within category & $\begin{array}{c}1.028^{* * *} \\
(0.00)\end{array}$ & $\begin{array}{c}1.124^{* * *} \\
(0.00)\end{array}$ & & \\
\hline median position within category & & & $\begin{array}{l}-0.198 \\
(0.73)\end{array}$ & $\begin{array}{l}-0.116 \\
(0.78)\end{array}$ \\
\hline constant & Yes & Yes & Yes & Yes \\
\hline number of main dishes on bill & No & Yes & No & Yes \\
\hline$N$ & 82100 & 82100 & 82100 & 82100 \\
\hline Log lik. & -9966.1 & -9896.3 & -9973.4 & -9904.4 \\
\hline AIC & 20092.1 & 20100.7 & 20102.9 & 20112.8 \\
\hline BIC & 20837.4 & 21535.3 & 20829.5 & 21528.8 \\
\hline
\end{tabular}

Notes: Estimates are based on a random draw from the full dataset. $P$-values in parentheses. ${ }^{*} \mathrm{p}<0.1,{ }^{* *} \mathrm{p}<0.05,{ }^{* * *} \mathrm{p}$ $<0.01$. 
Table 15: Panel fixed effects estimates of how the position of a dish is affected by past revenue

\begin{tabular}{|c|c|c|c|c|c|c|}
\hline \multirow{2}{*}{$\begin{array}{c}\text { panel FEs regression } \\
\text { revenue }(\mathrm{m}-1), \text { EUR in hundreds }\end{array}$} & \multicolumn{2}{|c|}{ first position } & \multicolumn{2}{|c|}{ last position } & \multicolumn{2}{|c|}{ median position } \\
\hline & $\begin{array}{c}-0.000770 \\
(0.83)\end{array}$ & $\begin{array}{c}0.00250 \\
(0.64)\end{array}$ & $\begin{array}{c}0.00726 \\
(0.59)\end{array}$ & $\begin{array}{c}0.0160 \\
(0.43)\end{array}$ & $\begin{array}{c}0.0210 \\
(0.19)\end{array}$ & $\begin{array}{c}0.0403 \\
(0.12)\end{array}$ \\
\hline Observations & 439 & 180 & 439 & 180 & 439 & 180 \\
\hline $\mathrm{R} 2$ & 0.00128 & 0.0369 & 0.00941 & 0.0219 & 0.0358 & 0.134 \\
\hline constant & Yes & Yes & Yes & Yes & Yes & Yes \\
\hline price $(m-1)$ & Yes & Yes & Yes & Yes & Yes & Yes \\
\hline business climate & Yes & Yes & Yes & Yes & Yes & Yes \\
\hline outside temperature & Yes & Yes & Yes & Yes & Yes & Yes \\
\hline AIC & -164.5 & -24.20 & -190.8 & -70.93 & 165.4 & 128.7 \\
\hline $\mathrm{BIC}$ & -148.2 & -11.43 & -174.5 & -58.16 & 181.7 & 141.4 \\
\hline
\end{tabular}

Notes: Estimates are based on a collapsed version of the full dataset, where for each of the 21 menu periods $m$, we observe $i$ dishes (the first period needs to be dropped in the estimations because of the lagged explanatory variable). Control variables comprise the price, the average business climate in the menu period and the average outside temperature to account for seasonality effects. Each included dish needs to be part of at least 2 menus. The second column of each model contains the results for a balanced panel to account for the fact that the restaurant owner may not only change positions, but also dishes over time. $P$-values in parentheses. ${ }^{*} \mathrm{p}<0.1,{ }^{* *} \mathrm{p}<0.05,{ }^{* * *} \mathrm{p}<0.01$.

Table 16: First stage estimates of the BLP-IV model

\begin{tabular}{lccc}
\hline \multicolumn{1}{c}{ BLP } & \multicolumn{2}{c}{ lagged position effect } \\
\cline { 2 - 4 } first position (m-1) & $0.756^{* * *}(0.00)$ & \\
& & $0.828^{* * *}$ \\
last position (m-1) & \multicolumn{3}{c}{$(0.00)$} \\
& & & $0.762^{* * *}$ \\
median position (m-1) & & & $(0.00)$ \\
& & & \\
outside temperature & 0.00124 & -0.000427 & -0.00182 \\
& $(0.52)$ & $(0.77)$ & $(0.49)$ \\
\hline Observations & 300 & 300 & 300 \\
Rsqu-adj. & 0.675 & 0.772 & 0.620 \\
F-stat & 125.9 & 247.1 & 203.2 \\
constant & Yes & Yes & Yes \\
\hline
\end{tabular}

Notes: Estimates are based on linear regressions. We use a collapsed version of the full dataset, where for each of the 21 menu periods $m$, we observe nine dishes continuously. Adding one outside (other) option per category (6) and period (21) and dropping the first menu period (due to the use of lagged variables as instruments) yields 300 observations. Business climate and group size variables were aggregated on the menu level. $P$-values in parentheses. ${ }^{*} \mathrm{p}<0.1,{ }^{* *} \mathrm{p}<0.05,{ }^{* * *} \mathrm{p}<0.01$. 
Table 17: BLP-IV estimates of the effect of position on choice

\begin{tabular}{|c|c|c|c|c|}
\hline \multirow{2}{*}{$\begin{array}{c}\text { BLP } \\
\text { price of item (per unit) }\end{array}$} & \multicolumn{2}{|c|}{ extremes } & \multicolumn{2}{|c|}{ median position } \\
\hline & $\begin{array}{c}-0.0179 \\
(0.20)\end{array}$ & $\begin{array}{c}0.0170 \\
(0.20)\end{array}$ & $\begin{array}{c}0.00563 \\
(0.68)\end{array}$ & $\begin{array}{c}0.00583 \\
(0.67)\end{array}$ \\
\hline last position within category & $\begin{array}{c}-0.316^{* * *} \\
(0.00)\end{array}$ & $\begin{array}{c}-0.304^{* * *} \\
(0.00)\end{array}$ & & \\
\hline first position within category & $\begin{array}{c}-0.355^{* * *} \\
(0.01)\end{array}$ & $\begin{array}{c}-0.346^{* * *} \\
(0.01)\end{array}$ & & \\
\hline median position within category & & & $\begin{array}{c}0.411^{* * *} \\
(0.00)\end{array}$ & $\begin{array}{c}0.411^{* * *} \\
(0.00)\end{array}$ \\
\hline Observations & 300 & 300 & 300 & 300 \\
\hline number of Halton draws & 1000 & 1000 & 1000 & 1000 \\
\hline constant & Yes & Yes & Yes & Yes \\
\hline average business climate & No & Yes & No & Yes \\
\hline average number of main dishes on bill & No & Yes & No & Yes \\
\hline
\end{tabular}

Notes: Estimates are based on a collapsed version of the full dataset, where for each of the 21 menu periods $m$, we observe nine dishes continuously. Adding one outside (other) option per category (6) and period (21) and dropping the first menu period (due to the use of lagged variables as instruments) yields 300 observations. We drop the first 100 elements when generating Halton sequences (burn). Instruments comprise lagged variables for the respective position and the outside temperature (to proxy seasonality). Business climate and the number of main dishes per bill were aggregated on the menu level. $P$-values in parentheses. $* \mathrm{p}<0.1,{ }^{*} \mathrm{p}<0.05, * * * \mathrm{p}<0.01$.

Table 18: Conditional logit full choice set, group size effects

\begin{tabular}{lcccc}
\hline & \multicolumn{2}{c}{1 main dish } & \multicolumn{2}{c}{ more than one main dish } \\
\hline price of item (per unit) & -0.208 & -0.210 & $-0.187^{* *}$ & $-0.189^{* *}$ \\
& $(0.54)$ & $(0.54)$ & $(0.02)$ & $(0.02)$ \\
first position within category & 0.156 & & 0.0598 & \\
& $(0.67)$ & & $(0.56)$ & \\
last position within category & -0.271 & & $-0.199^{* * *}$ & \\
& $(0.42)$ & & $(0.01)$ & \\
median position within category & & 0.0556 & & 0.0281 \\
& & $(0.84)$ & & $(0.65)$ \\
constant & Yes & Yes & Yes & Yes \\
\hline$N$ & 5474 & 5474 & 76018 & 76018 \\
Log lik. & -586.1 & -586.5 & -9240.2 & -9243.8 \\
AIC & 1326.3 & 1325.1 & 18634.4 & 18639.5 \\
BIC & 1835.1 & 1827.3 & 19345.8 & 19341.7 \\
\hline
\end{tabular}

Notes: Estimates are based on a random draw from the full dataset. $P$-values in parentheses. Very large groups (more than 12 individuals) are excluded in this analysis. These groups make up for less than $0.3 \%$ of the sample. In these groups the compromise effect is no longer apparent. ${ }^{*} \mathrm{p}<0.1,{ }^{* *} \mathrm{p}<0.05,{ }^{* * *} \mathrm{p}<0.01$. 